Illinois State University

ISU ReD: Research and eData

Theses and Dissertations

7-3-2019

\title{
An Intersectional Examination of Criminally Involved Women of Color with Mental IIIness
}

Cailin Rosemary McDermott

Illinois State University, cailinmcdermott@gmail.com

Follow this and additional works at: https://ir.library.illinoisstate.edu/etd

Part of the Criminology Commons, and the Criminology and Criminal Justice Commons

\section{Recommended Citation}

McDermott, Cailin Rosemary, "An Intersectional Examination of Criminally Involved Women of Color with Mental Illness" (2019). Theses and Dissertations. 1155.

https://ir.library.illinoisstate.edu/etd/1155

This Thesis is brought to you for free and open access by ISU ReD: Research and eData. It has been accepted for inclusion in Theses and Dissertations by an authorized administrator of ISU ReD: Research and eData. For more information, please contact ISUReD@ilstu.edu. 


\section{AN INTERSECTIONAL EXAMINATION OF CRIMINALLY INVOLVED WOMEN OF COLOR WITH MENTAL ILLNESS}

\section{CAILIN ROSEMARY McDERMOTT}

\section{Pages}

Women, women of color, and women with mental illness are fast growing populations in the criminal justice system. Research, to date, however, has tended to overlook women of color with mental illness who exist at the intersection of these statuses. The current thesis examines an intersectional framework regarding the analysis of the narratives of these multifaceted women to explore the ways that their varying positions in society interact and shape unique life experiences. An analysis of a secondary data set of semi-structured life-course interviews with sixty-five women on a Seriously Mentally Ill (SMI) probation caseload in Maricopa County, Arizona was conducted to explore this. Implementing a grounded-inspired approach, the interviews were coded and compared in order to uncover emergent intersectional themes. While analyses reveal racial disparities in lived experiences, the narratives in the current sample demonstrate that the women of color did not attribute disadvantageous life circumstances and events specifically to their race. While these women face stigmatization on various fronts, it is possible the marginalization they endure based on their interacting statuses is executed in a complex and surreptitious manner which might enable them to attribute their subjugation to only part of their multifaceted identity. The intricacies of intersectionality can be imperceptible to researchers and their subjects. However, with rising numbers of criminally involved women who exist within multiple positions of oppression, criminologists must explore these intricacies and 
conduct inclusive research that is cognizant of the diverse experiences of those who fall within different intersections of marginalization, while also examining larger patterns of oppression and privilege in the criminal justice system.

KEYWORDS: intersectionality, mental illness, criminalization, social control 


\section{AN INTERSECTIONAL EXAMINATION OF CRIMINALLY INVOLVED WOMEN OF}

COLOR WITH MENTAL ILLNESS

CAILIN ROSEMARY McDERMOTT

A Thesis Submitted in Partial

Fulfillment of the Requirements

for the Degree of

MASTER OF SCIENCE

Department of Criminal Justice Sciences

ILLINOIS STATE UNIVERSITY 
(C) 2019 Cailin Rosemary McDermott 


\section{AN INTERSECTIONAL EXAMINATION OF CRIMINALLY INVOLVED WOMEN OF}

COLOR WITH MENTAL ILLNESS

CAILIN ROSEMARY McDERMOTT

COMMITTEE MEMBERS:

Philip Mulvey, Chair

Shelly Clevenger

Cara Rabe-Hemp 


\section{ACKNOWLEDGMENTS}

This thesis has been the culmination of more faith, second chances, and patience than I ever could have deemed myself worthy of. I need to thank Dr. Phil Mulvey for that. You saw something in me that I had a hard time seeing in myself for a long time. You invested in me, even though it was a risk. I have not forgotten the books you lent me when I could not afford them, nor have I overlooked how understanding you were when I had to leave the program years ago. You had every chance to shut the door on me, but you welcomed me back to finish what I started at Illinois State without hesitation. You've always seen my potential and pushed me to reach it, even if it meant calling just to listen to me sigh loudly into the void for six straight minutes before reassuring me that I could still do this. Your faith in me was all the reassurance I needed to know that I was really doing something right. Thank you. Endlessly.

Thank you to Dr. Rabe-Hemp and Dr. Clevenger for being power houses of feminine energy and strength in a field that I wasn't sure I had a place in as a woman. Because of your compassion and accomplishments, I am sure, now, more than ever, that I belong here. Your unwavering support and confidence in me throughout my academic career has gotten me this far. Your passion for helping others, giving voices to those who have been silenced, and changing the world through your work is what will continue to push me further. Thank you.

Mom and Dad, your love and support has powered me through this. I do what I do because I love it, but also because I love you. You worked tirelessly and sacrificed so much so that I could get this education. I have not taken that for granted. Thank you for giving me this life.

Lastly, I am infinitely indebted to these sixty-five women for sharing such deeply intimate accounts of their lives with us. You inspire me. You are heard. Your voice makes a difference.

C.R.M. 


\section{CONTENTS}

$\begin{array}{lll}\text { Page } & \end{array}$

ACKNOWLEDGMENTS

CONTENTS

CHAPTER I: INTRODUCTION 1

Statement of the Problem 1

Description and Purpose of Study $\quad 4$

CHAPTER II: LITERATURE REVIEW

Women in Criminal Justice $\quad 6$

The Social Control of Women of Color $\quad 8$

The Criminalization of Women 9

$\begin{array}{ll}\text { The Criminalization of Women of Color } & 12\end{array}$

Poverty and Social Exclusion of Women in the Criminal Justice System 17

Women of Color with Mental Illnesses $\quad 20$

Black Women with Mental Illnesses $\quad 21$

Latina-Americans with Mental Illnesses $\quad 22$

Native American Women with Mental Illnesses 23

The Criminalization of Mental Illness $\quad 24$

$\begin{array}{ll}\text { Intersectionality } & 27\end{array}$

Black Feminism and Intersectionality 29

$\begin{array}{ll}\text { Crenshaw’s Intersectionality } & 30\end{array}$

$\begin{array}{ll}\text { Intersectional Criminology } & 31\end{array}$

Construction of Crime 33 
Current Focus

Data Collection and Setting

Sampling, Data Collection, Participants, and Procedure

Intersectionality and Qualitative Interviewing

Grounded Theory and Analysis

Rhetoric About Stigmatization

Diagnoses

Race, Diagnosis, and Crime

Institutionalization and Medicalization

Intersectional Identities Shaped through Power and Control

Experiences of Abuse

Experiences of Addiction

Experiences of Sex Work

Illuminating Intersectionality

Changing Policy 


\section{CHAPTER I: INTRODUCTION}

\section{Statement of the Problem}

The last forty years of criminal justice policy has been permeated with aggressive anticrime rhetoric that has led to unprecedented growth in incarceration rates, especially in regard to non-violent drug offenses (Alexander, 2010; Rojas, Smith, \& Scott-McLaughlin II, 2017). Scholars acknowledge that these rising incarceration rates have disproportionately impacted lower-income, racial minority men (Barak, Leighton, \& Cotton, 2015), yet much of this research has failed to address the less commonly considered victims of this era of mass incarceration women. The lack of focus on empirical analysis examining criminally involved women is especially noteworthy, as the number of women in prison increased at a rate of $586 \%$ between 1980 and 2011, which was almost 1.5-times the rate of men (Minton and Golinelli, 2014). The rising number of women in jails and prisons has been so pronounced that, between 2010 and 2013, when the population of incarcerated men had actually declined by $4.2 \%$, the population of incarcerated women continued to increase by another 10.9\% (Rojas, Smith, \& Scott-McLaughlin II, 2017). Women are also under the control of probation and parole agencies in record numbers. In 1995, there were roughly 750,000 women on probation and parole (Morash, 2010), and by 2016, women made up $22 \%$ of all probationers and $12 \%$ of all parolees, equaling about 913,058 women under community supervision (Kaeble, 2018). When added to the 2016 incarcerated population of 111,616 women (Carson, 2018), there are now well over one million women under the control of the criminal justice system.

The alarming rate at which women are now entering the criminal justice system is only exasperated by the disproportionately high rates of criminalization faced by Black women. Toward the end of the 1980s and into the 1990s, the arrest rates of Black women for drug charges grew by 
$828 \%$, which was triple the rate faced by White women for the same crimes during that time and double the percentage increase faced by Black men (Bush-Baskette, 1998). By the early 2000s, one in every three-hundred Black women had been incarcerated, which was roughly double the rate at which Latinas were incarcerated and triple the rate at which White women were (Thompson, 2013). Criminally involved Black women face discrimination based on both their gender and race that has led to their disproportionate representation in the system. This marginalization is compounded when considering Black women with mental illnesses.

It is hard to definitively calculate how many women of color in the criminal justice system suffer from mental illnesses due to the varying and discretionary nature of psychiatric treatment within the system and lack of focused research on this marginalized group. However, existing estimates paint a grim picture of how prevalent mental health issues are among this population. When characterizing typical criminally involved women, not only are they disproportionately poor women of color who face discrimination based on their race, gender, and socioeconomic status, but they are also often the mothers of young children, victims of substantial trauma and abuse, and suffer from substance abuse and mental health issues at higher rates than criminally involved men (Bloom, Owen, \& Covington, 2003). According to the U.S. Department of Justice ([DOJ], 2006a), $23 \%$ of women in prisons reported having been diagnosed with a mental illness in the past twelve months, whereas only about $8 \%$ of men in prisons reported having been diagnosed with a mental illness in that same timeframe. Other studies have shown that upwards of $80 \%$ of incarcerated women exhibited evidence of at least one psychiatric disorder in their lifetime (Jordan, Schlenger, Fairbank, \& Caddell, 1996). According to the National Alliance on Mental Illness (NAMI), African Americans are about 20\% more likely to experience serious mental illness than the rest of the population. Considering the high rates of mental illness experienced by women and criminally 
involved individuals, it is expected that criminally involved Black women suffer from mental illness at disproportionately high rates.

For nearly two centuries, Black feminists have examined this critical interaction between race and gender (Potter, 2013), the effect of which has manifested itself through the increasing criminalization of poor women of color. In 1989, critical race theorist Kimberlé Crenshaw introduced this concept to criminal justice discourse, coining the term "intersectionality," which is defined as the way that gender links and interacts with other forms of oppressed statuses, such as race, ethnicity, class, sexuality, disability, age, and religion (Lykke, 2010; Mehrotra, 2010; Sandberg, 2013). Crenshaw theorized that Black women face discrimination that is different from the gender discrimination faced by White women and the racial discrimination faced by Black men, as they sit in the intersection of these two oppressed statuses, which creates a unique, multiplicative position of marginalization. Crenshaw was the first to explicitly tie the concept into criminal justice literature by viewing it in the context of antidiscrimination law.

Criminological research, however, has traditionally focused on demographic factors such as race, gender, class, and mental health status in a way that has been inherently mutually exclusive, citing one or the other as being significant in an individual's experiences, but failing to acknowledge the ways in which these factors interact with each other in the lives of individuals to create unique and varied experiences (Trahan, 2011). This traditional approach fails to examine the bigger issues of marginalization of women of color and the significant differences between offenders and victims alike who fall within these intersections, especially at a time when the number of poor women of color in the criminal justice system is soaring (Barak et al., 2015; Chesney-Lind, 2006). In response to this negligence, a variety of feminists, criminologists, and other social scientists have made marked efforts to advance their scholarship through an 
intersectional lens, contributing to an emerging field of intersectional criminology. Intersectional criminology is a "theoretical approach that necessitates a critical reflection on the impact of interconnected identities and statuses of individuals and groups in relation to their experiences with crime, the social control of crime, and any crime-related issues" (Potter, 2013, p. 305). To ignore intersectionality in current criminological research is to be "theoretically misguided, politically irrelevant, or simply fantastical" (Davis, 2008, p. 68).

\section{Description and Purpose of Study}

Women of color, poor women, and women with mental illnesses are over-represented and growing populations in the criminal justice system. These women are particularly marginalized in terms of race and gender, yet there has been little consideration in the literature about how mental illness adds to that marginalization. Consequently, the goal of the current thesis is to expand upon this topic by exploring how race, gender, mental illness, and life circumstances interact to shape the life-course and experiences of women with mental illness who are criminally involved. The current thesis seeks to explore this topic by examining the narratives of these women with mental illness through an intersectional lens. The current study adds to the field of intersectional research in criminally involved individuals by expanding upon gender and race to also explore the important consideration of mental illness. Furthermore, it does so by examining the experiences of criminally involved women in their own voices - a specific perspective often absent in the field of criminal justice and this topic of study specifically.

To explore the intersectional influences and experiences of criminally involved women with mental illness, the current study will analyze sixty-five qualitative, semi-structured life-course interviews with women who were assigned to a Severely Mentally Ill (SMI) probation caseload in Maricopa County, Arizona during a fourteen-month period. Past research has shown that women, 
minorities, and individuals with mental illnesses face significant, unique issues that are amplified when they are placed under the control of the criminal justice system (Harrison-Ross \& Lawrence, 2009). Therefore, women of color with mental illnesses are expected to face significant barriers during their time in corrections due to the multiplicative nature of their marginalized statuses (Harrison-Ross \& Lawrence, 2009).

As noted above, there is a substantial amount of research on people of color in the criminal justice system, however, far less research considers the intersections of race, gender, class, and mental health statuses of these individuals. Additionally, the rate of incarcerated women is continuing to grow at a time that general incarceration rates are beginning to decline (Barak et al., 2015; Rojas et al., 2017). As a result, it is imperative that scholars examine this population in criminology, and even more critical that they do so through an intersectional lens. Through indepth analyses rooted in intersectional feminist theory, this thesis hopes to provide insight into the experiences of these women, the reasons that they may have engaged in crime, and their treatment within the criminal justice system, with extensive focus on the roles that their gender, race and ethnicity, and mental health status played in each of these areas of their lives. 


\section{CHAPTER II: LITERATURE REVIEW}

\section{Women in Criminal Justice}

American historian Cynthia Eagle Russett (1989) explained, "Women and savages, together with idiots, criminals, and pathological monstrosities, were a constant source of anxiety to male intellectuals in the late nineteenth century" (p. 63). Much of this anxiety was centered around the inability to understand why women would willingly defy their prescribed gender roles of being subservient, docile mothers and wives to engage in masculinized criminal activity. This inability to understand criminal women was reflected in early criminological literature that framed them as monstrous failures of evolution (Lombroso \& Ferrero, 1895) who were "almost entirely devoid of any gentle or redeeming trait" (Adam, 1914, p. 3). Early criminologists viewed criminal women as disregarding the "virtuous restraints of society" and therefore "enlisted on the side of evil" (Carpenter, 1864, p.32), making them far worse than criminal men (Adam, 1914).

This inability to reconcile with the fact that women are complex, multifaceted human beings that are capable of criminality, produced the Madonna-whore complex. The dichotomization of women into "Madonnas" or "whores" is evidence of the inability to understand that women can be good and bad in the same ways that men are without putting their status as women at risk. Role-conforming, submissive women are designated as "Madonnas," and those who do not meet the strict criteria of the "Madonna" role are deemed "whores" and criminal (Belknap, 2000). It has been argued that this dichotomization becomes further complicated when considering its application to women of color. Dr. Vernetta Young ( 986) challenged the existing Madonna-whore complex by explaining that women of color are not even afforded the privilege of a "good girl" category, but instead are given varying "bad girl" labels to which they are assigned (Young, 1986; Belknap, 2000). 
The preoccupation with categorizing women as being "good" or "bad" fails to acknowledge their unique circumstances as individuals and their complicated status as women in a society that has historically restricted their access to resources, privileges, and power due to their gender (Ayman \& Korabik, 2010; Datchi \& Ancis, 2017). To label women as simply good or bad ignores the fact that the intersections of race, gender, and class have a tremendous influence on their lives in ways that shape their needs, motivations, and subsequent criminality (Barak et al., 2015; Bernard, 2013).

Scholars have also examined the role of paternalism and chivalry in the treatment of women in the criminal justice system. Chivalry is the tendency to view women as being too fragile to care for themselves, necessitating that they be removed from "risky situations" (Datchi \& Ancis, 2017 , p. 2). It is marked by a reluctance to harm these women or to believe their potential of criminality (Moulds, 1980; Barak et al., 2015). Paternalism is more indicative of the power imbalances between women and men (Nagel \& Hagan, 1983; Kruttschnitt \& Savolainen, 2009). Unlike chivalry, which denies that women are capable of committing crimes, paternalism suggests that women simply cannot be held responsible for their actions because of their status in the patriarchy (Moulds, 1980; Barak et al., 2015).

Women who so violently fall outside of the range of what society is willing to treat with chivalry or paternalism are ascribed to be "evil women." This view argues that women will be treated more harshly than men if they have committed crimes that are deemed to be in violation of prescribed gender roles (Kruttschnitt \& Savolainen, 2009). It suggests that criminal women are biologically flawed (Gentry \& Sjoberg, 2015) and that their deviation from traditional feminine behavior is to blame for their wrongdoings (Berrington \& Honkatukia, 2002). 


\section{The Social Control of Women of Color}

Historically, women have been controlled through informal social institutions (e.g., family systems) much more frequently than through formal social institutions (e.g., the criminal justice system) (Carlen, 2002). For this reason, among others, there are significantly fewer criminally involved women than men. While women once made up a "substantial portion" of felony offenders (Feeley \& Little, 1991), the removal of women from the formal economy and their placement into the informal social control and supervision of their husbands has contributed to a smaller population of women in corrections. Even when women make it far enough in the criminal justice system to see a court date, they are less likely to be seen as criminals and more likely to be seen as "maddened or misguided victims of a variety of malign social circumstances" (Carlen, 2002, p. 4). This view of women as being "mad, not bad" (Zedner, 1991, p. 264) historically led to deviant women being medicalized rather than penalized, through placement into psychiatric institutions (Barak et al., 2015). However, in the wake of the decimation of psychiatric institutions in the United States and the weakening of informal institutions of social control (e.g., family systems), the criminal justice system has been tasked with controlling "deviant" women (Boritch \& Hagan, 1990).

Howe (1990) explained, "Social control - like criminality - is profoundly gendered” (p. 50). The expectation that women adhere to the strict gender norms to which they are prescribed is yet another way they are controlled within the context of criminology. Schur (1984) explained that these gender norms explicitly work as "mechanism[s] for the social control of women" (p. 52) in that they are labeled as deviant no matter what they do if it falls out of the strict confines of their gendered roles and expectations (Thompson, 2005). This notion is especially evident in how poor women, women of color, and women with mental illnesses are controlled within the criminal 
justice system, both through laws that primarily target women, such as prostitution and abortion legislation (Danner, 1999), and through the ways that officials label criminally involved women as mentally ill more than criminally involved men (Offen, 1986; Thompson, 2010). Furthermore, scholars have also highlighted the disproportionate exploitation of and control over poor women of color (Barak et al., 2015).

Marxist theories of social control suggest that racial minorities are viewed as threats to the social order, which has shaped the law to target and punish these groups (Bridges \& Steen, 1998). While White women have historically been controlled through informal social institutions (e.g., family structures) or psychiatric hospitalization (Brewer \& Heitzeg, 2008; Davis, 2003), women of color have long been controlled through formal institutions such as incarceration and slavery (Butler, 1997; Chesney-Lind, 1996). The institutionalization of women of color has been consistently linked with their subjugation by White Americans, from the rising number of Black women in jails since the Civil War (Rafter, 1985) to the forced enrollment of Native Americans into violent boarding schools tasked with assimilating them to White American culture (Perry, 2006; Stannard, 1992) to the criminalization of Mexicans in attempts to claim the Southwest long ago and to propel anti-immigrant legislation today (Muñoz \& Martínez, 2001). Although the number of women in the criminal justice system is growing at an unprecedented rate, the criminalization of women of color is nothing if not consistent.

\section{The Criminalization of Women}

Since the 1990s, the rates of incarcerated women have doubled (Rowan-Szal, Joe, Simpson, Greener, \& Vance, 2009). Not only have they doubled, but they have done so at a rate that is significantly greater than that of men. In the years between 1995 and 2004, the number of incarcerated women had increased nearly 53\%, while the number of incarcerated men increased 
by only 32\% (Beck, 2005). Between 1986 and 1999, the number of women sentenced for nonviolent, drug-related crimes jumped by over $800 \%$ (American Civil Liberties Union [ACLU], 2005; Datchi \& Ancis, 2017). Importantly, as the incarceration rate of women increased, the incarceration rate of men was actually decreasing (Chesney-Lind, 2006). Between 1989 and 1998, the populations of girls' detention facilities grew by $56 \%$ while the populations of boys' facilities grew by only $20 \%$. This growth in incarcerated girls disproportionately consisted of young, Black girls, who make up only about $12 \%$ of the general population but nearly half of young girls in detention facilities (Chesney-Lind, 2006; Barak et al., 2015).

The most dramatic increases in rates of arrest and incarceration of women began in the mid-eighties to early-nineties, at the same time as the advent of the "War on Drugs." Policies put in place during this era resulted in women being arrested more frequently and incarcerated for longer periods of time for non-violent, drug crimes (Lilliot, Trott, Kellett, Green, \& Willging, 2017). While drug use and selling occur at fairly similar rates across races and ethnicities, Black and Latina women have been criminalized at far higher rates than White women (Drug Policy Alliance, 2016; Ritchie, 2017). For this reason, scholars have argued that the War on Drugs is a "largely unannounced war on women, particularly women of color" (Ritchie, 2017; Zaplin, 1999, p. xiv).

Women are most commonly arrested for crimes that reflect their typically low socioeconomic status and limited resources, such as property or drug crimes (Bloom, Owen, \& Covington, 2004; Rojas et al., 2017). It is unsurprising, then, that the War on Drugs has so dramatically impacted women, specifically poor women of color. The deliberate framing of criminally involved women as "evil women" and "whores" in early criminology has resurfaced and manifested itself through the "crack whore" and "welfare queen" rhetoric of the War on Drugs. 
Meda Chesney-Lind (2006) explained that the "media demonization" and "masculinization" of criminally involved women, entwined with the "criminalization of women's victimization," have effectively fueled this mass increase in the arrest and incarceration of women, which disproportionately targets women of color (p. 10).

Not only are women the fastest growing group of individuals in the criminal justice system, but they also face a myriad of unique issues in comparison to criminally involved men. For one, incarcerated women are significantly more likely to have had custody of their children prior to entering the system. Of the $80 \%$ of women entering prison who are mothers (Belknap, 2000), few reported having a support system in place for their children, with only about $10 \%$ reporting that the children's fathers cared for them during their incarceration (Glick \& Neto, 1982; Rafter, 1985).

Women who are incarcerated are also significantly more likely to face serious health problems, both physically and mentally, due to their "increased likelihood of living in poverty, limited access to preventative health care, poor nutrition, chemical dependency, and limited education on health matters" (Belknap, 2000, p. 109). In a 1989 survey of jail inmates, it was found that incarcerated women were also more likely than incarcerated men to report drug use, both generally and in terms of frequency of use and seriousness of drugs (Belknap, 2000; DOJ, 1991).

Criminally involved women also face significant difficulty upon re-entry due to their economic marginalization, which is marked by limited access to resources, health care, and public assistance (Lilliot et al., 2017). The difficulty that these women encounter in trying to attain these important predictors of successful reentry increases their risk of recidivating (Willging, Malcoe, St. Cyr, Zywiak, \& Lapham, 2013), overdosing on drugs, or committing suicide shortly following their release (Binswanger et al., 2007). 
Heindesohn (1985) suggested that criminologists must acknowledge the social control and marginalization of women in order to understand women and crime. Women have been historically criminalized based on their adherence, or lack thereof, to their gender roles, which has created an institution of gendered discrimination. The obsessive dichotomization and labeling of women as "deviants" has overwhelmingly failed to acknowledge the complexity of gender, status, and social control and how women experience these things in relation to their socioeconomic status, race and ethnicity, as well as other marginalized positions.

\section{The Criminalization of Women of Color}

In the criminal justice system, women of color are monitored (Crenshaw, 2012; Datchi \& Ancis, 2017), arrested (Haft, 1976), sentenced (Brennan, 2006), and incarcerated (Brewer \& Heitzeg, 2008; Datchi, 2017) at significantly higher rates than any other demographic. As discussed above, while the population of incarcerated men had grown three-fold over a span of two decades, the incarcerated population of women had increased tenfold, with Black women being three-times more likely to be incarcerated than Latinas and six-times more likely to be incarcerated than White women (Brewer \& Heitzeg, 2008; DOJ, 2004). Researchers have theorized reasons for this disparate treatment of women of color in the criminal justice system, including higher rates of poverty, longer criminal records, less access to legitimate opportunities, and a higher risk of being labeled criminal (Belknap, 2001; Brennan, 2006).

Importantly, research has found that criminal justice officials tend to view minority offenders more negatively than they view White offenders. Minority offenders are more often seen to be dangerous, predatory, disrespectful towards authority, and inclined toward offending and reoffending (Bridges \& Steen, 1998; Cicourel, 1968; Peterson \& Hagan, 1985) by criminal justice officials, which, when combined with their socioeconomic status and other aggravating factors, 
has led to a disproportionate number of boys, girls, men, and women of color being pushed through the criminal justice system. It is unsurprising, then, that women of color, who exist in the nexus of being perceived as criminal due to their skin color and being perceived as criminal due to their failure to adhere to White gender norms, are disproportionally represented in the criminal justice system.

The criminalization of Black women. Unfortunately, a large portion of criminal justice research has fallen into an "essentialism trap" when considering gender and race in that they tend to equate "women" with "White women" and "minorities" with "Black men," effectively erasing the prevalence and importance of gender and racial differences within each category (Alcoff, 1988; Goodkind, 2005; Harris, 1990; Narayan, 1997; Omi \& Winant, 1994). This places Black women in between "Black criminology" (Rice, 2016) and "feminist criminology," causing them to be largely overshadowed in a vast majority of the literature (Brown, 1986). Rice (2016) recognized that the "seeming invisibility of Black women creates false impressions about the extent and nature of their involvement in criminal activity" (p. 59) despite the fact that research consistently shows that they are stereotyped and discriminated against as much as Black men in the criminal justice system (Lewis, 1977). In fact, some scholars have pointed to higher rates of Black inmates in women's prisons than in men's prisons (Belknap, 2001). By mid-2008, 349 of every 100,000 Black women were incarcerated, compared to a rate of 93 of every 100,000 White women (Thompson, 2010). Despite fairly equal amounts of reported drug use across all races, Black women are also three-times more likely to be sentenced for drug offenses than White women (Mauer, 2013).

Perceptions of Black women as being deviant from the strict terms of White femininity have been a driving force behind their criminalization. In a society that places much weight on the passivity, dependency, and chastity of women, stereotypes of the independent and defiant Black 
woman pose significant threats (Chigwada-Bailey, 2008). Rice (2016) suggested that, in the face of social pains caused by racism and segregation, Black girls have been forced to adapt by developing subcultural values stressing "strength, independence, resilience, and perseverance" (p. 60) that directly contradict White standards of femininity. Instead of being viewed as "feminine, fragile, and deserving of protection" (Belknap, 2000, p. 73), Black women are viewed as being completely culpable for their criminal actions, a "suitable enemy" (Chigwada-Bailey, 2008, p. 29) worthy of punishment. So much so that mitigating factors that benefit White women, such as being responsible for a child or suffering from substance abuse issues, typically do not benefit Black women (Chigwada-Bailey, 2008).

The criminalization of Latinas. Muñoz and Martínez (2001) explained that the propensity of the criminal justice system to dichotomize issues of race into Black or White categories "precludes a serious examination into the possibility of divergent patterns and levels of criminality among other racial/ethnic groups" (p. 151). Consequently, and also due to the fact that Latin Americans have historically been and continue to be categorized within racial and ethnic groups other than their own (Muñoz \& Martínez, 2001), Latinas have been largely ignored in criminal justice research despite the fact that they represented one seventh of women in state prisons and one third of women in federal prisons in 1999 (Diaz-Cotto, 2006; Oparah, 2005). Latinas are also charged with alcohol, drug, and property crimes at much higher rates than their White counterparts (Muñoz \& Martínez, 2001). Additionally, Mann (1984) found that Latinas living in New York made up $28.8 \%$ of women arrested for drug crimes, but upwards of $41.2 \%$ of the women incarcerated for drug offenses, suggesting a much higher sentencing rate (Mann, 1984; Oparah, 2005). Oparah (2005) explained that not only do Latinas have the highest rates of recidivism, but they are also disproportionately arrested, convicted, and sentenced in the criminal 
justice system. The research has also shown that Latinas are more likely to be perceived as being "drug couriers" by criminal justice officials than Latinos, putting them at a higher risk for being stopped and searched on the premise of hunting for drugs than men or Whites (Green, 1996; Oparah, 2005).

Latinas face a myriad of stereotypes centered around their perceived hyper-sexuality and relation to drug-trafficking. They are often labeled as "sexy women of easy virtue" (Castro, 1998, p. 134), drug users, welfare queens (Brennan, 2006), and gang members or the "irresponsible mothers of gang members" (Portillos, 1998, p. 162). The societal and political endorsement of these stereotypes allows for sustained criminalization of Latina girls and women. Additionally, research tends to equate all Latinas as being from a homogenous group despite coming from a multitude of different backgrounds. The experiences of Latinas differ in terms of "race, socioeconomic status, power, sexuality, immigration status, language issues, family structure, relational status, power dynamics, and geographical location (urban, immigrant, non-immigrant)" (Bermúdez, Stinson, Zak-Hunter, \& Abrams, 2011, p. 639). To essentialize the experiences of all Latinas as one contributes to their stigmatization and alienation in society and in the criminal justice system.

The criminalization of Native American women. In 2008, Native Americans constituted only about $3.6 \%$ of the U.S. population, yet they were five-times more likely than White Americans to find themselves in the criminal justice system (Tonry, 1994). Even though Native Americans are disproportionately involved in the criminal justice system, they still make up only about $1 \%$ of total arrests nationwide, so there is a paucity of data on this population, especially when considering Native American women. The majority of existing research has explored the high victimization rates of Native Americans, which are about twice that of the national average 
(DOJ, 2004), but has failed to acknowledge the criminalization of this population. Existing theories about the criminalization of Native Americans are dated and limited in scope and tend to treat the population as a homogenous group, undifferentiated by tribe, gender, location, or otherwise, which fails to acknowledge the vastly different cultures and experiences of Native Americans across the country (Ulmer \& Bradley, 2017). For this reason, there exists almost no specific theory or research on the criminality of Native American women.

One proposed reason for the disproportionate criminalization of Native Americans as a whole, however, is "internal colonialism" (Snipp, 1986; 1992). Internal colonialism is defined as when a "more powerful majority physically, socially, and/or culturally isolates an indigenous people, and maintains economically exploitive relations toward that minority" (Ulmer \& Bradley, 2017, p. 2). This internal colonialism effectively depletes the resources within communities that predict the success of its inhabitants.

Negative stereotypes and attitudes held about Native Americans are also cited as being responsible for their criminalization. Common stereotypes of Native Americans as lazy, violent alcoholics (Chang \& Kleiner, 2003) not only promote anti-Native biases in the criminal justice system (Ulmer \& Bradley, 2017), but also embolden the "discriminatory application of the law" against Native Americans (Alvarez \& Bachman, 1996, p. 550; Zatz, Lujan, \& Snyder-Joy, 1991).

The disenfranchisement of Native communities through colonialism is not only manifested through stereotypes held by other groups, but it is often internalized by Native Americans. This creates a culture in which Natives Americans might even identify with their aggressors in harming themselves and their communities (Brave Heart, 1995; Brave Heart \& DeBruyan, 1996; Poupart, 2002). Scholars have linked self-image and crime among Native Americans, finding that Native Americans with poor self-image are at greater risk to find themselves within the confines of the 
criminal justice system (Alvarez \& Bachman, 1996; Flute, Grobsmith, \& Revenaugh, 1985; Grobsmith, 1989; May, 1986). Some have cited the destruction of the culture and image of Native Americans through forced assimilation, Indian schools, and social isolation as being responsible for the poor self-image among Natives (Lujan, 1995; Wilkenson, 1974).

Additionally, Native Americans have historically poor relationships with the police. Police have often acted as the front line of anti-Native policies and actions, making them a symbol of the violent American government for Native Americans (Perry, 2006). Perry (2006) found that many Native Americans felt they were mistreated by police through both outwardly racist remarks and actions and failure of police to act when they were needed. On the other end, many Native Americans reported feeling over-policed in that they perceived police officers as being more willing to criminalize them and aggressively respond to alleged crimes than they were willing to accept them as victims and respond to victimization

\section{Poverty and Social Exclusion of Women in the Criminal Justice System}

Researchers have found that criminally involved women are often products of environments plagued by poverty, poor education, violence, sexual and physical abuse, substance abuse, homelessness, sexual exploitation, poor physical and mental health, normalized criminal activity, and racism (Social Exclusion Unit [SEU], 2002). Chigwada-Bailey (2008) argued that women of color face a combination of oppressed statuses that create a "greater potential for unequal treatment" (p. 19), including the issues that affect their racial/ethnic group due to their existence in a White society, the issues that affect them as women living in a patriarchal society, and the issues that affect them as citizens living in poverty in a capitalist society.

As of 2010, women in the United States were, as a whole, $32 \%$ more likely to be living in poverty than American men (Legal Momentum, 2010). This high rate of poverty among women 
most dramatically impacts women of color. In the early $2000 \mathrm{~s}, 10.7 \%$ of White women lived below the poverty line, however, more than twice as many women of color did. Recent research has found that one-quarter of all Black, Latina, and Native American women live in poverty (Entmacher, Robbins, Vogtman, \& Morrison, 2014). In 2015, one-quarter of Latinas lived below the poverty line and more than half lived in conditions considered to be near-poverty (Gándara, 2015) and in 1998, Latinas as a whole had the lowest median income of any demographic (Hernandez-Truyol, 1998). Rojas et al. (2017) explained that the high rates of poverty for women of color forces them into the nexus of the oppressive forces of classism, racism, and sexism, which persists throughout their lives and especially in their criminal justice experiences.

Poverty also plays an especially detrimental role in the subjugation of Native American women. Historical treatment of Natives has forced them into a position of economic dependence on government welfare (Poupart, 2002). Because of the isolated nature of the typical reservation, Native Americans have a markedly more difficult time accessing government services on which they are likely to rely, have high rates of unemployment, and are subjected to under-funded education systems (Poupart, 2002). The isolation from these important pillars of society and higher levels of social, political, and economic deprivation has had a direct impact on crime and violence within Native communities (Poupart, 2002).

Scholars have illustrated that the typical criminally involved woman is young, economically disadvantaged, part of a minority group, uneducated, unmarried, and a single mother (Arnold, 1990; Mann, 1984). It has also been found that incarcerated Black women are more likely to have come from poverty and more than twice as likely to have been on welfare upon their arrest than incarcerated White women (Arnold, 1990; Glick \& Neto, 1977; Lewis \& Bresler, 1981). The high rates of poverty experienced by women of color, as noted specifically in the literature about 
Black women, complicates their life experiences in ways that both push them into the criminal justice system and exacerbate disadvantaged conditions that cause high-rates of recidivism.

Persistent poverty also creates barriers for women of color in terms of education, legitimate career opportunities, and availability of health care (Carlen, 2002; Datchi, 2017), which creates exceptionally stressful conditions for women of color that might force them to turn to crime as a means of survival or to turn to substance abuse as a means of coping. Lemert (1967) argued that this lack of opportunity, both economically and socially, increases the chance that an individual will become involved in crime. Arnold (1990) described criminal behavior in young, poor, Black girls as often being acts of "active resistance to victimization" (p. 153) rather than deviant in nature.

Poverty combines with other societal factors to create a unique form of marginalization for women of color. Lower economic status reduces access to political power, which is why the values upheld by the law represent the interests of upper-class Americans at the expense of those living in poverty. Therefore, impoverished minority Americans are most likely to be subjected to the control of the law due to their poverty-associated lives and behavior being deemed criminal by the upper-class law-makers (Chigwada-Bailey, 2008). Poverty, in linkage with racism, has also been found to have a significant impact on mental health, with rates of depression more than $50 \%$ higher in economically unstable people of color (Sharpley, Hutchinson, Murray, \& McKenzie, 2001).

Race and gender discrimination significantly impact the lives of women of color, and the pains they suffer are greatly exacerbated by the conditions of poverty in which many women of color are forced to live. In a society that already works hard to prevent economic and social opportunities for this disadvantaged group, poverty magnifies their difficulties in ways that increase the chances that women of color will find themselves vulnerable to substance abuse 
(Datchi, 2017), turning to crime as a means of survival (Arnold 1990), and, consequently, incarcerated (Chigwada-Bailey, 2008).

\section{Women of Color with Mental Illnesses}

Scholars have suggested that women are reported to have mental illnesses at higher rates than men, and women of color not only have unique experiences with mental illness, but also face substantial barriers in terms of treatment (Harrison-Ross \& Lawrence, 2009). The high rates of poverty experienced by women of color is cited as a risk factor for mental health issues (Kessler et al., 2003) as well as a reason for why they are less likely to seek out or receive adequate mental health care (Abe-Kim et al., 2007; Alegria et al., 2007a; Nadeem et al., 2009; Neighbors et al., 2007; U.S. Department of Health and Human Services, 2001). This results in a higher rate of suffering from negative outcomes of untreated mental health issues (Ruiz, 2002).

In addition to holding generally negative attitudes toward mental health and mental health treatment (Keefe, 1981; Leaf, Bruce, Tischler, \& Holzer, 1987; Nadeem et al., 2009; Padilla \& Salgado de Snyder, 1988; Silva de Crane \& Spielberger, 1981; Snow, 1983), being a poor person of color has also been cited as a barrier to treatment among minorities. Alvidrez (1999) found that lack of insurance, time, and transportation resulted in lower rates of service use among poor, minority Americans with mental health issues. However, even identically insured Latino and African Americans were still less likely to use mental health services than White Americans (Padgett, Patrick, Burns, \& Schlesinger, 1994a; 1994b; Scheffler \& Miller, 1989).

Despite overall high rates of mental health issues among poor women of color, lower economic status and cultural perceptions of mental illness have led to lower rates of help-seeking and treatment. Importantly, minorities are also more likely than Whites to be labeled as mentally 
ill by "distant professionals," particularly the police (Horwitz, 2002), placing them in uniquely difficult positions in the age of criminalizing mental illness.

\section{Black Women with Mental IIInesses}

Vespa (2009) explained that “Black women's joint race-gender identity is more salient for their mental health than either the identities Black or woman alone" (p. 366). Mental health issues are particularly prominent amongst Black women, with approximately $60 \%$ reporting having experienced symptoms of depression (Ward, Clark, \& Heidrich, 2009). Researchers have suggested several possible causes for mental health issues among Black women, including low socioeconomic status (Chigwada-Bailey, 2008; Thompson 2010) and the "double minority" status of their racial and gender identities (Tausig, Michello, \& Subedi, 1999; Thompson, 2010; Ward et al., 2009, p. 1).

Financial strain is a significant predictor of mental illness and has been found to increase the chance of someone developing depression by over 50\% (Chigwada-Bailey, 2008). Some research has found that socioeconomic status was such a strong predictor of mental health issues that properly controlling for it could effectively erase the racial disparities in mental illness (Dohrenwend \& Dohrenwend, 1969; 1974; Frerichs, Aneshensel, \& Clark, 1981; Kessler, 1979; Kessler et al., 1994; Schultz et al., 2000; Warheit, Holzer, \& Avery, 1975; Warheit, Holzer, \& Schwab, 1973).

Nevertheless, the relationship between socioeconomic status and race are not so easy to separate in the real world. Thompson (2010) explained that African Americans might be at higher risk of suffering from mental health issues due to exposure to stressors based on their racial identities because they are continuously placed at a disadvantage when compared to equally educated and experienced White individuals (Pager, 2007; Tausig et al., 1999). McKenzie and 
colleagues (2001) ascertained that there is a strong association between racism and likelihood of developing a mental illness, with victims of racist incidents being upwards of 2.5-times more likely to develop depression and 4.5-times more likely to develop schizophrenia than those who have not been victims of racist incidents. Additionally, Villarosa (1994) concluded that the cultural pressure to internalize pain placed on Black women in particular can also lead to higher rates of mental health issues with lower rates of help-seeking and treatment.

On the other hand, there are also implications concerning the under-diagnosing of African Americans because of their race. Kutchins and Kirk (1997) suggested that deeply rooted stereotypes about the criminality of African Americans can cloud how others might perceive their mental illnesses in that people might interpret symptoms to be criminal behavior because of their internalized biases.

\section{Latina-Americans with Mental Illnesses}

In 2007 , it was found that over $30 \%$ of Latinas had experienced a mental health issue over their lifetime (Alegria et al., 2007b). Latinas are also almost two-times more likely to have been diagnosed with a mood or anxiety disorder than Latinos (Alegria et al., 2007a). Additionally, Latinas are the least likely to seek out mental health services of any ethnic group, contributing to overall higher levels of untreated mental health issues and associated difficulties (Alegria et al., 2002; Blanco et al., 2007; Wang et al., 2005; Weinick, Zuvekas, \& Cohen, 2000). However, there are countless different ethnic subgroups of Latinxs in the United States and the majority of research on mental health in these populations is gender-neutral in nature, so it is not advisable to assume or generalize causes of mental health issues across so many varying cultures and lifestyles. 


\section{Native American Women with Mental Illnesses}

The amalgamation of research on the mental health of Native Americans finds disproportionately high rates of suicide and suicide attempts (Indian Health Services [IHS], 2001; May, 1987; Yates, 1987), post-traumatic stress disorder, alcohol abuse and dependency (Beals, Novins, Whitesell, Spice, Mitchell, \& Manson, 2005; Johnson \& Cameron, 2001; Yates, 1987), and anxiety and depression (Duran et al., 2004). Napholz (1995), citing McGrath and colleagues (1990), stated, "Compared with other women, the health and mental health status of American Indian women is generally worse" (p. 57-58).

The overall adjusted suicide mortality rate of Native Americans is $72 \%$ greater than all other races in the United States (IHS, 1999). In a population of Native American girls in boarding schools in the late 1980s, researchers found that they were more disposed to depression and further research found that $20 \%$ of all Native American girls have attempted to commit suicide (De' Andre, 1994; Johnson \& Cameron, 2001; LaFromboise, Berman, \& Sohi, 1994). The Indian Health Service (1995) postulated that $21 \%$ of the total Native American and Alaska Native population was affected by mental illness or self-destructive behavior.

Native American women are uniquely placed in the position of having to balance their responsibilities to their family, tribe, and nation in the wake of effective cultural decimation through colonization (Napholz, 1995) while also having to adapt to the majority culture as working-class women who are overrepresented in low-status occupations with lower wages and education than their White counterparts (Gordon-Bradshaw, 1987; Kopasci \& Faulkner, 1988; Lin $\mathrm{Fu}, 1987)$. Welch (1987) explained the "bicultural stress" experienced by working-class Native American women as the culmination of social and cultural isolation, the stress of being employed outside of their tribal community, and familial obligations. This bicultural stress is only 
exacerbated within Native American cultures that exhibit high levels of male dominance and control over women. Napholz (1995) suggested that these "culturally sanctioned subordinate gender roles among certain tribal groups may contribute to depressive symptomology among those American Indian women" (p. 58), finding that Native women who strictly adhered to their gender roles were more likely to be depressed and to exhibit low self-esteem and low life satisfaction (Napholz, 1995).

Most research on Native American women explores the exponentially high rates of victimization they face in comparison to national averages. Native American women suffer from overall rates of victimization in terms of sexual assault, rape, simple and aggravated assault, serious violent crime, and intimate partner violence higher than any other group of women in the United States (Bohn, 2003; Evans-Campbell, Lindorst, Huang, \& Walters, 2006; Rennison, 2001; Tjaden \& Thoennes, 2000). High rates of victimization among Native American women has been associated with a higher risk of suicide (Blum, Harmon, Harris, Bergeison, \& Resnick, 1992; Pharris, Resnick, \& Blum, 1997), PTSD (Robin, Chester, Rasmussen, Jaranson, \& Goldman, 1997), depression, and substance abuse (Evans-Campbell et al., 2006; Hamby \& Skupien, 1998). Therefore, it is crucial to examine the role of victimization in the development of mental disorders among Native American women, as well as the development of substance abuse issues, that may lead to subsequent criminalization.

\section{The Criminalization of Mental Illness}

The institutionalization of women as a form of social control has been a significant part of American culture since the asylums of the nineteenth century. However, in the wake of deinstitutionalization, these long-standing institutions were closed across the nation, leaving society to find new forms of social control, which in turn, led to the criminalization of mental 
illness (Lamb, Weinberger, \& Gross, 1999; Shadish, Lurigio, \& Lewis, 1989). It is estimated that over two million arrests per year involve individuals with serious mental health issues and that more than half a million inmates in jails and prisons in the United States have a severe mental illness (Lish, 2016). Between 1998 and 2006, the number of incarcerated individuals with mental health issues more than quadrupled (DOJ, 2006a; 2006b). It has been posited that alarming rates of homelessness (Martell, Rosener, \& Harmon, 1995), low public tolerance for the individuals with mental illnesses (Torrey, 1997), the stigmatization of individuals with mental illnesses as being violent and dangerous (Durham, 1989) have worked together to fuel this criminalization of mental illness.

Criminally involved women are the fastest growing population in the criminal justice system and are significantly more likely to be suffering from mental health issues than criminally involved men (Thompson, 2010). The marginalization of women and widespread violence against them has had a tremendous impact on both their mental health and criminal involvement. Criminally involved women are unique from criminally involved men in that they are more likely to have experienced significant trauma and abuse that has served as a pathway into the system and that they are more likely to possess distinctive mental health issues (Daly 1992; 1993; HarrisonRoss \& Lawrence, 2009). Similarly, battered women who find themselves criminally involved are also at substantial risk of suffering from depression, PTSD, and addiction (Markham, 2003).

The psychiatric treatment of women has been an instrument of social control since the days of the asylum. Bridges and Beretta (1994, p. 163) stated that "one social institution that has been instrumental in the control of women, apart from prisons, is the psychiatric treatment of the mentally ill." They explained that women have historically been more vulnerable to being diagnosed and labeled as mentally ill than men and that this vulnerability has followed them in 
their experiences with the criminal justice system. In studies of health care in prisons, researchers have found that institutions use psychotropic medications as a form of control over incarcerated women, which Spieglman (1977) called “chemical pacification." Shaw's (1982) findings asserted that women in prison were medicated at anywhere between twice to ten-times the rate of men across institutions. Additionally, women who had engaged in violent offenses were medicated at higher rates than those who had not (Auerhahn \& Leonard, 2000).

However, with the dissolution of most large psychiatric facilities in the United States, these "deviant" women find themselves situated in a different institution of massive social control - the criminal justice system. The number of women with mental health issues in prisons and jails largely exceeds the averages for the general population. James and Glaze (2006) found that nearly $12 \%$ of women experience mental health issues in the general population, and that that number skyrockets to up to $73 \%$ of women incarcerated in state prisons, $61 \%$ of women incarcerated in federal prisons, and $75 \%$ of women incarcerated in local jails. Upwards of one-third of women in jails and prisons suffer from severe mental illnesses (Ditton, 1999; James \& Glaze, 2006). Some studies suggest that as many as $80 \%$ of incarcerated women have had at least one psychiatric disorder over their lifetime (Jordan et al., 1996; Teplin, Abram, \& McClellan, 1996). Thompson (2010) theorized that this overrepresentation of women with mental illnesses in the criminal justice system could be due to either a legitimately higher rate of mental health disorders among incarcerated women or a prison system that diagnoses incarcerated women more frequently than incarcerated men.

Despite the fact that some states refer more than twice as many women to specialty mental health caseloads than men (Lord, 2002), their psychiatric needs are not adequately addressed by available programs, services, and treatment during or post-incarceration. Due to there being fewer 
correctional institutions for women, far fewer programs and services exist for women than in men's institutions (Abramsky \& Fellner, 2003). This is especially evident in their derisory medical and mental health care. Even if women's prisons were to implement the same services that exist in men's institutions, they may not be adequate for women due to their "vastly different pathways into jails, patterns of mental disorder, family responsibilities, and trauma and abuse histories" (Harrison-Ross \& Lawrence, 2009, p. 126). As long as deviant women continue to be diagnosed as mentally ill at elevated rates, women are also susceptible to inappropriate use of drugs and lengthened sentences under the guise of treatment (Baskin, Sommers, Tessler, \& Steadman, 1989).

\section{Intersectionality}

"The fact is I am brown and female, and my growth and development are tied to the entire community. I must nurture and develop brown self, women, man, and child. I must address the issues of my own oppression and survival. When I separate them, isolate them, and ignore them, I separate, isolate, and ignore myself. I am a unit. A part of brownness.” (Canaan 2015, p. 234)

Theories of anti-essentialism and the scholarship of Black feminist emphasize that all women do not experience the world in the same way, which is a fundamental component of intersectionality (Potter, 2013). Intersectionality is the understanding that the human experience is multifaceted and consists of "multiple, layered identities, derived from social relations, history and the operations of structures of power" (Murphy, 2009; Symington, 2004, p. 2). Potter (2013) noted that intersectionality has "multiplicative social effects on an individual's identit[y]" (p. 305). In its essence, intersectionality is the way in which gender and other oppressed statuses, such as race, class, and disability, are fundamentally connected to each other and how these "socially constructed categories of oppression and privilege" constantly interact with each other to create unique experiences (Lykke, 2010; Mehrortra, 2010; Murphy, 2009, p. 7; Sandberg, 2013). 
An important feature of intersectionality is the multiplicative nature of it, in that demographics such as race, class, gender, and disability cannot be viewed separately, nor can they simply be stacked together in an additive nature, but they must be viewed in "multiple and interactive terms" (Daly, 1993, p. 56). Even though one might find their race or gender to be more salient in certain situations, they are always working "multiplicatively to shape one's social location" (Burgess-Proctor, 2006, p. 36) and are "overlapping and cumulative in their effect on people's experience" (Anderson \& Collins, 2004, p. 7). These systems of oppression cannot be studied individually because they are "created, maintained, and transformed simultaneously and in relationship to one another" (Weber, 2010, p. 127). Patricia Hill Collins (1990) theorized that distinctive systems, or "axes", of oppression, such as gender and race, are part of an "overarching structure of domination" (p. 222) that work together to create diverse experiences of subjugation based upon an individual's unique circumstances that fall within that "structured whole" (Conaghan, 2008, p. 37) of oppression.

Another critical feature of intersectionality, specifically as it pertains to criminology, is the role of power within the framework. Baca Zinn and Thornton Dill (1996) advised that it is important to acknowledge that the social structures which oppress some individuals simultaneously benefit others, highlighting the "relational nature of dominance and subordination" of intersectionality, and explaining that these power relations are what differentiate women from one another. For this reason, intersectionality is not reserved only for women of color, who are situated in a position of severe disadvantage in our society, but for men and women of all races and classes, as they are impacted by these power structures as well, be it in a negative or positive way (Baca Zinn \& Thornton Dill, 1996; Burgess-Proctor, 2006). Race, class, gender, and other categories of inequality are "dynamic, historically grounded, socially constructed power 
relationships that simultaneously operate at both the micro-structural and macro-structural level" (Burgess-Proctor, 2006, p. 37).

\section{Black Feminism and Intersectionality}

Black feminists played a pivotal role in the development of intersectionality. Black feminism is focused on the unique experiences of women of color in terms of the oppressions they face based upon their gender and race (Burgess-Proctor, 2006; Crenshaw, 1989; Hill Collins, 1990). Feminist women of color have long argued that it is impossible to separate race, class, and gender because they operate in "interlocking patterns" which shape and have been shaped by systems of domination that significantly impact the lives and experiences of individuals (Anderson, 1996; Murphy, 2009).

Despite the seeming lack of reverence for Black feminism and intersectionality in modern scholarship, it is by no means a new concept. In the mid-nineteenth century, the first African American women to earn a doctorate, Dr. Anna Julia Cooper, wrote:

...the colored woman of today occupies, one may say, a unique position in this country. In a period itself transitional and unsettled, her status seems one of the least ascertainable and definitive of all the forces which make for our civilization. She is confronted by both a woman question and a race problem, and is as yet an unknown or unacknowledged factor in both... (Cooper, 1990[1834], p. 134)

In 1940, civil rights activist Mary Church Terrell expressed that Black women were a unique population in the United States in that they had to overcome difficulties they faced due to their race and gender whereas White women and men of color only had to overcome difficulties they faced due to race or gender (Murphy, 2009). Similarly, bell hooks (1984) posited that it “...has been easier for women who do not experience race or class oppression to focus exclusively on gender." In 1991, Crenshaw concluded that Black women are both marginalized in anti-racist politics because of their gender and feminist politics because of their race. 
The issues faced by women of color that are addressed within intersectionality are pervasive and deep-rooted, having been written about at least as far back as the 1830s. However, despite the tireless efforts of Black feminists across academia, there remains a significant void where there should be more exploration into the topic. This is especially problematic as it pertains to criminology given that those who are most criminalized in America are also those who sit at these intersecting forms of marginalization that are examined in intersectionality. Thanks to Kimberlé Crenshaw's introduction of the concept to criminological lexicon, however, there has been a slight shift in favor of this type of theorizing.

\section{Crenshaw's Intersectionality}

In 1989, Kimberlé Crenshaw brought the long-standing problem of intersectionality to the discourse of law and criminology for the first time through her groundbreaking scholarship that explored discrimination in the workplace for Black women. Crenshaw's (1989) initial conception of the term "intersectionality" was focused on Black women and the ways in which their gendered and racial identities intersected in their lived experiences in a way that was ignored by antidiscrimination doctrines, which were “defined respectively by White women's and Black men's experiences" (Crenshaw, 1989, p. 142-143). Crenshaw cited that there were "problematic consequence[s] of the tendency to treat race and gender as mutually exclusive categories of experience and analysis" (p. 139).

Crenshaw went on to write several more ground-breaking pieces regarding intersectionality, developing three conceptions of the ways in which women of color experience the intersection of race and gender: structurally, representationally, and politically. Structurally, Black women are situated as "lower status identities" (Settles, 2006, p. 589) in America due to their race and gender, making them vulnerable to racism and sexism by dominant groups as well 
as their own groups, such as White women and Black men. Representationally, Crenshaw referred to the ways in which the media depicts Black women through damaging stereotypes alluding to hyper-sexual and domineering natures (West, 1995; 2004). And politically, Crenshaw cited the tension between conflicting goals of African Americans and women which might cause Black women to feel "torn between the potentially conflicting ideas, beliefs, and aims of the social and political groups that claim to represent women and those that claim to represent blacks" (Settles, 2006, p. 590). Through her work, Crenshaw was one of the first to introduce an intersectional framework to legal theory and, subsequently, criminal theory, leading to the advent of intersectional criminology.

\section{Intersectional Criminology}

Potter (2013) defined intersectional criminology as "a theoretical approach that necessitates a critical reflection on the impact of interconnected identities and statuses of individuals and groups in relation to their experiences with crime, the social control of crime, and any crime-related issues" (p. 305) which is grounded in intersectionality and Black feminism. Only by centering intersectional criminology around the experiences of Black women and other women of color can researchers hope to understand the "gender policing and racialized punishment" (Oparah, 2012, p. 257) they face which has turned the prison into "an essential site for the subordination" (Ocen, 2013, p. 474) of women of color. Intersectional feminists and criminologists attempt to move past rigorous quantitative research of individuals towards a more exploratory, qualitative approach which can better examine the ways in which individual characteristics and systems of oppression work to shape unique life experiences that impact one's involvement in the criminal justice system (Burgess-Proctor, 2006; Weber \& Parra-Medina, 2003). Due to the multiplicative nature of intersectionality, a combination of qualitative and quantitative research is 
necessary in order to adequately examine the nuanced relationship between race, class, and gender (Barak et al. 2015). Burgess-Proctor summarized that, in order to reach an understanding of crime, justice, and gender, that "achieves universal relevance and is free from the shortcomings of past ways of thinking" (2006, p. 28), criminologists must acknowledge and explore the connections between inequality and crime through a multiracial and intersectional framework.

To date, a handful of criminologists have taken on the difficult task of adequately applying intersectionality to criminal theory. Lynch (1996) theorized a linkage between race, class, gender, and crime through a life-course lens with a focus on how existing in these marginalized social statuses can shape the decisions individuals make leading to their involvement in crime. In the same year, Richie (1996) coined the term "gender entrapment" to explain the ways in which victimized women, particularly those who are also poor and of color, find themselves "forced or coerced into crime by their culturally expected gender roles, the violence in their intimate relationships, and their social position in broader society" (p. 133). Maher (1997) examined how race, class, and gender interact in the experiences of women involved in street-level drug crime, stating that researchers can no longer accept "class-based explanations" of crime, but instead need to examine the more "complex set of cross-cutting influences" such as gender, race, and immigrant status, among other things (Maher, 1997, p. 169). Barak (1998) emphasized the importance of acknowledging the "differences in the patterns of crime attributed to socialization, opportunities, and bias in the context that everyone's life is framed by inequalities of race, class, and gender" (p. 251). Steffensmeier and colleagues (1998) concluded that it was vital to consider "the joint effects of race, gender, and age on sentencing" as well as the importance of "using interactive rather than additive models" (p. 763). 
Historically, women of color have been categorized in terms of either their race or gender, leaving a chasm in research that allows for continued uninformed stereotyping of women of color that impacts the way they are treated as both victims and offenders in the criminal justice system (Young, 1986). Structural inequalities based on class, gender, and race manifest through varying experiences in crime and crime control (Barak et al., 2015), therefore it is critical to examine not just the experiences of men and women or African Americans or White Americans, but how these statuses overlap, intersect, and interact throughout the lives of individuals, particularly women of color.

\section{Construction of Crime}

Feminist criminologists have gone further to examine how class, gender, and race are pillars through which society has constructed crime, deviance, and normalcy, leaving certain members of society more vulnerable to being labeled as deviant and punished because of it (Daly \& Stephens, 1995). Barak and colleagues explained that structured action theories of criminology relate to intersectionality in that they acknowledge how cultural conceptions of what is masculine or feminine interacts with the race and class of individuals to shape crime and justice (2015). Black and Mileski (1973) suggested that, when traditional forms of social control are weakened, criminal law is shaped in response to better control subordinate groups and this criminal social control is gendered and classed in nature, with poor women of color being most at risk of being subjected to this formal regulation (Boritch \& Hagan, 1990). Predictably, the offenses of the powerless are punished more often and more severely than those of the powerful (Barak et al., 2015).

Nunn (2002) argued that racism persists in a supposedly post-racial society by manifesting itself through crime control, a widely accepted reaction to transgression and deviance. By deeming the conduct of particular groups as being criminal, those who create and benefit from the law are 
able to criminalize individuals based on their race without explicitly saying so, and this clandestine criminalization can be and is extended to other social groups such as women and the poor.

\section{Poverty and Intersectionality}

Poverty plays a pivotal role in the intersectional experiences and criminalization of women of color. So much so that Murphy (2009) postulated that it represents the "ultimate accumulation and articulation of social inequalities related to the multiple discriminations individuals are more likely to encounter when located at the intersection of two or more oppressing social relations" (p. 334). Barak and colleagues (2015) suggested that persons from minority racial and ethnic categories frequently share a common experience of poverty, marked by employment, housing, and education discrimination that significantly and negatively impact their lives. They expanded upon the fact that a long-standing history of racism against people of color has disproportionately relegated these individuals to a position in which race and class are tied together inextricably to make them much more vulnerable to "exploitation and control by the criminal justice system" (Barak et al., 2015, p. 107). Barak (2003) explained that these impoverished groups are "structurally violated" (p. 116) throughout their lives due to the fact that concentrated poverty in minority communities has decimated the "foundations of life and the integrity of local institutions" (Barak et al., 2015, p. 116).

Gamble (1999) argued that the relationship between gender and class for women is arbitrated by "the configuration of the family, dependence on men, and domestic labour" (p. 206). Poor women of color are particularly vulnerable in that they may experience oppression from not only Whites, but from members of their own race, gender, and class based upon their comparatively marginalized status (Danner, 1999). Danner further contended that women of color are placed in a subordinate position to upper-class men that directly impacts the unequal 
distribution of material resources that is reflected in the rates at which they are criminalized (Danner, 1999; Hurtado, 1989).

This “violent legac[y] of colonialism, male domination, and marginalization" (Lilliot et al., 2017, p. 130) has effectively devastated public services and material supports crucial to the success of a community, placing women of color in a double-bind that not only puts them at substantially greater risk of suffering from persistent poverty, but allows for their being persistently stereotyped as being deviant failures worthy of surveillance and punishment (Crenshaw, 2012; Ocen, 2012).

The propensity to frame poor women of color as being shady recipients of welfare, undeserving of public assistance, perpetrated through images of "crack mothers" and "welfare queens" has made them exceptionally vulnerable to surveillance by the government, particularly through law enforcement. These standing stereotypes accusing Black women of playing the system of public aid has created an image of presumed deviance and criminality of poor women of color that has allowed for increased levels of surveillance and monitoring that would not be tolerated with any other group, which makes them exceptionally vulnerable to police surveillance and subsequent involvement in the criminal justice system (Crenshaw, 2012; Ocen, 2012).

Scholars have also argued that Black women are uniquely targeted by society as being responsible for the crimes of Black men and women alike by being viewed as "incubators of criminal activity" (Crenshaw, 2012; Moynihan, 1993; Ocen, 2012, p. 1562). Senator Moynihan (1993) stated that the Black community "asks for and gets chaos" because of the high rates of women-headed households, essentially relegating the blame of criminality among African Americans to the fact that they are more likely to be raised without a father figure and, more insidiously, speculating that Black women and mothers as a whole are to blame for criminality in the Black community. 
It is by framing poor Black women as being insincere in their reception of public aid and as being to blame for high rates of crime in Black communities, that society has permitted this discriminatory type of investigation and scrutiny of Black women. This oppression faced by women of color due to their race, gender, and class has not only served to increase their involvement with the criminal justice system, but also takes a toll on their mental health. Settles (2006) found that the combined gender and racial identities of Black women had more of an impact on their mental health status than their roles as women or roles as African Americans alone proved to. Draine and colleagues (2002) suggested that the role of socioeconomic status in mental health was so strong, in fact, that poverty actually "moderates the relationship between serious mental illness and social problems" (p. 565). Therefore, poor women of color are at exceptional risk of suffering from a mental illness due to their gendered, raced, and classed position in society.

Intersectionality acknowledges that one's status and position in society is determined and shaped by their gender, race, and socioeconomic status and that women of color are especially marginalized and vulnerable in ways that have been difficult to observe through traditional lenses of criminology (Bernard, 2013). The propensity to categorize women of color based on simply their gender or their race while ignoring the interaction of the two has led to a full body of scholarship that lacks sincere depth and understanding of their plights. There must be a delicate balance of examining the diversity and uniqueness of individuals who fall within different intersections of oppressed groups while simultaneously understanding the patterns of oppression and privilege that are prominent in crime and social control (Barak et al., 2015). Arnold (1990) called for a reexamination of the ways in which researchers view the lives of women of color, who are persistently victimized because of their gender, race, and class in ways that influence their being labeled as deviant. By viewing their lives through an intersectional lens, researchers are 
better able to "legitimate the experiences of women who have been marginalized and hidden from the dominant cultural discourses" (Sokoloff \& Dupont, 2005, p. 49) and to grasp how the criminal justice system has evolved in a way that has led to the mass incarceration of poor women of color with mental illnesses, who exist in a societal position that makes them especially "vulnerable and incarcerable" (Ocen, 2013, p. 474).

\section{Current Focus}

Women have been criminalized at unprecedented rates in the last forty years, at a frequency that is outpacing men (Rojas et al., 2017). Furthermore, this rising criminalization also disproportionately impacts women of color (Chesney-Lind, 2006), poor women (Barak et al., 2015), and women with mental illnesses (Thompson, 2010). Yet most of the existing research allows for the experiences of these women to be essentialized based on their race or gender without consideration for the intersectional impact of their positions in society. The failure to acknowledge the "multiplicative and interactive" (Daly, 1993, p. 56) effect of race, gender, class, mental health status, sexuality, and other oppressed factors on these women lends to their being continuously stereotyped, stigmatized, and subsequently criminalized (Crenshaw, 2012; Lewis, 1977; Rice, 2016; Young, 1986).

The existing research on criminally involved women of color typically falls in the realm of statistical analyses of the demographics without much attention paid to their lived experiences and the intersectional influences of their positions as criminally involved women of color who have mental illnesses. Intersectional criminologists have made strides to examine the intersections of race and gender in criminal justice, but most of this research simply explores the differences between Black women and White women, failing to integrate their varying mental health experiences, a significant factor for many criminally involved women. Additionally, the propensity 
to examine intersectionality through comparing Black and White women precludes an inclusive and comprehensive body of work that should consider other women of color who have been less represented in the research, such as Latina and Native Americans. Through the in-depth, intersectional analysis of sixty-five life-course interviews with women on an SMI probation caseload, this thesis seeks to explore the intersections of race, gender, socioeconomic status, and mental health on criminally involved women's experiences in their own words. While this group of women is only a particular subset of a much larger population of marginalized women, this thesis and its findings hope to shed a light into their experiences and the adversity that they face. The intention is to add not only to research about criminally involved women of different races and ethnicities with mental illnesses, but to a growing body of research that applies intersectional theory to criminology. 


\section{CHAPTER III: METHODOLOGY}

\section{Data Collection and Setting}

The current data were collected over a fourteen-month period at Maricopa County Adult Probation Department (MCADP) in the Phoenix metro region. At the time of data collection there were approximately 52,000 individuals under the supervision of MCAPD, which is composed of nineteen offices staffed by just over one thousand employees (MCAPD, 2013). The department has a variety of specialty caseloads and courts. Included in these are a veteran's court, drug court, and a Seriously Mentally Ill (SMI) specialty probation caseload. The SMI caseload is characterized as a problem-solving initiative which aims to provide its clients with the tools and treatment necessary to ensure their success. Additionally, this program offers probationers the opportunity to have their felony convictions reduced to misdemeanors and to be more swiftly released from custody (MCAPD, 2018).

This SMI caseload began in 1995 with a single supervisor and a few SMI caseload probation officers. At the time of data collection, the SMI unit had the ability to serve up to 680 SMI probationers, with seventeen specialty caseload probation officers and two supervisors overseeing the supervision of over six-hundred probation clients (daily average) (Mulvey, 2013). Standard probation officers at MCAPD supervised up to eighty offenders on their caseloads, whereas the SMI unit officers were limited to a maximum of forty offenders (MCAPD, 2013). MCAPD reported a completion rate of $73 \%$ among SMI probationers at that time.

In order for a probationer to be considered for the SMI unit, they needed to have either a DSM-IV-TR Axis I diagnosable mental health disorder or qualifying traumatic brain injury (MCAPD, 2013) and noteworthy functional impairment, such as a history of suicide attempts or psychiatric hospitalizations (Mulvey, 2013). At the time of data collection there were two primary 
ways that a probationer could have been placed on the SMI caseload - either through the referral of the sentencing judge or the screening probation officer. If a sentencing judge recognized the aforementioned characteristics in an offender, they could refer them to the SMI unit, where the probation officers had discretion on whether or not to admit them to this problem-solving program. Alternatively, if a probation officer recognized that a client had significant mental health issues during their initial screening into general adult probation (or at any time during standard probation supervision), the intake and standard officers had the discretion to refer the individual to the SMI caseload. An SMI caseload screening officer would then meet with the individual and complete an assessment to deem whether the individual was a good fit for the SMI case load.

\section{Sampling, Data Collection, Participants, and Procedure}

The current thesis draws from secondary data analysis of sixty-five interviews with women on the SMI caseload during a fourteen-month period in the last ten years. ${ }^{1}$ At the time of the interviews, women represented 30\% of MCAPD's SMI probation unit, totaling two-hundred probationers. The original study sought to interview roughly one-third of the women on SMI probation during that time period, resulting in sixty-five semi-structured qualitative interviews. To be a part of the study, potential participants were approached following their regularly scheduled meetings with their probation officers and offered the opportunity to participate in the study. Those who expressed interest in participating were given a flyer with more information and were later interviewed. The interviews were completed in private probation offices with only the researcher

\footnotetext{
${ }^{1}$ The officer makes this determination by completing a full review of the probationer's case file, consulting with the standard officer, and administering an assessment created specifically by the SMI department at Maricopa County for SMI probation eligibility.
} 
present. In some cases, interviews were completed in a private room at the in-patient treatment facilities where a few of the women were residing.

The semi-structured qualitative interviews ranged from forty-five to ninety minutes in length. The interview was laid out so as to explore the daily lives of the participants, their childhoods, their personal and legal relationships, their mental health, their substance abuse, and their criminal involvement. This was done so in a way that allowed the participants to lead the conversation and elaborate where they saw fit, and for the interviewer to ask follow-up questions for clarification throughout the interview. It would have been inappropriate to assign each participant to the same strict interview template without consideration for their unique and complex experiences, so it was vital to allow for the interview to evolve with what the participants shared with the researcher.

Of the sixty-five participants interviewed, at least two came from each active SMI probation officer's caseload represented in the sample. Each of these interviews were audiorecorded and the participants were given a \$20 gift card as a thank you for their participation. Following the interviews, the recordings were transcribed by a professional transcriptionist and checked for accuracy by university research assistants.

\section{Intersectionality and Qualitative Interviewing}

The type of qualitative interviewing exhibited in this dataset is critical in employing an intersectional analysis of these women and their experiences, allowing for the development of a “deep mutual understanding” of the participants (Miller \& Glassner, 2011). Due to the fact that intersectionality is focused on the relationships and interactions between oppressed statuses, it is imperative to not only look at quantitative data that measures these demographics, but to employ qualitative measures that are better able to explore the "nuanced meanings of class, race, gender, 
and their intersections" (Barak et al., 2015, p. 154). Britton (2004) argued that criminologists have relegated important parts of intersectionality "to the background for the sake of methodological convenience" (p. 71), feeding into the damaging inclination to essentialize women in criminal justice (Burgess-Proctor, 2006). Bernard (2013) explained that intersectional researchers should not strive to make their results generalizable, but to ground findings in the individual experiences of the women we are interviewing in order to "demystify and humanize their lived experiences and perspectives while providing a range of practical explanations" (Bernard, 2013, p. 9) for their decisions and behavior.

The endless combinations of race, gender, class, mental health status, and other demographic statuses that are represented among criminally involved women cannot be neatly and easily categorized as they would have to be in quantitative research (Jiwani, 2006; Trahan, 2011). Rather than representing distinct values that can be entered into a table, race, class, and gender interact constantly in a way that "reflect[s] the interdependence of privilege and oppression, as well as crime and conformity" (Trahan 2011, p. 4). Therefore, they cannot be adequately examined through "rigid quantitative frameworks" (Trahan 2011, p. 3). In order for academics to appropriately examine intersectional identities, they must explore the impact of not just demographic categories, but the influence of environmental, cultural, and social forces on one's life through the "rich descriptive accounts of the contextual nature of people's lived experiences" (Baca Zinn, Hondagneu-Sotelo, \& Messner, 2005; Trahan, 2011, p. 3).

Trahan (2011) delved into the importance of combining quantitative and qualitative data when examining a population through an intersectional lens. He cited the dimension of the definition of intersectionality highlighting the role of "overlapping systems of oppression that operate simultaneously" (p. 12), concluding that it is only logical that we also combine and 
integrate our data sources to analyze this concept. By combining these two types of research, researchers not only double up on their benefits, but are able to make up for the weaknesses of one with the strengths of the other (Johnson \& Turner, 2003; Trahan, 2011).

\section{Grounded Theory and Analysis}

The nature of intersectionality necessitates a grounded-inspired theoretical approach. Grounded theory is inductive in nature and centered around observations and emergent analysis (Bachman et al., 2012; Glaser \& Strauss, 1967). Grounded theory is critical in qualitative analyses in that it allows for researchers to consider the complicated circumstances and factors in the lives of individuals and the settings in which they live in a way that lends to the development of logical explanations and theory. In consideration of the role of intersectionality in the lives of criminally involved women, this is especially true. One cannot expect to understand how race, gender, and class have impacted a particular woman without first hearing her story and then building upon that. To go into these analyses with presumptions about their experiences would be remiss and a failure to truly acknowledge the staples of intersectionality that highlight the complexity of these status roles in the lives of each individual.

It is important to note my reflexivity as the author of this thesis. Reflexivity refers to the personal experiences and feelings of the researcher on a topic and how these experiences and feelings have the potential to shape how data is interpreted throughout the process (Creswell, 2016). I have personal experience with individuals with mental illnesses, some of whom have been criminally involved, which has caused me to be inherently empathetic to this population. Additionally, I have worked with a probation caseload that involved individuals with mental illnesses as part as an undergraduate internship, which has given me first-hand involvement with a population similar to that being studied in this thesis. It is also crucial to disclose that I am not a 
woman of color and I have not been involved in the criminal justice system. Therefore, I cannot expect to fully understand the struggles and experiences of the participants being explored in this thesis. For that reason, and out of respect for the nature of intersectionality, I will be diligent in addressing my privileged status as a White woman, my reflexivity on the topic, and will consciously set aside my personal views on the topic by noting my own reactions, feelings, and observations so as to avoid pushing them onto the analysis of the date. The use of a groundedinspired approach which develops findings from these women's stories and their stories alone will assist in setting aside any preconceived notions I might hold about the information.

This grounded-inspired approach, which will construct themes based on observations across these interviews, is derived from grounded theory and emergent analysis. Grounded theory is based on the concept of "emergence," which allows researchers to develop theories that emerge from a dataset which account for what the data shows (Charmaz, 2008). Grounded and emergent theories have the ability to evolve throughout the process of analysis based on data and findings and to acknowledge unexpected findings in ways that more quantitative theories may not be able to (Charmaz, 2008). However, grounded theory should not stand on its own and be employed without consideration for existing theory. Instead, it should be used in application. Researchers should be open to all theoretical possibilities when examining data and build upon emergent observations to develop theory appropriate to these observations (Charmaz, 2008)

The dataset for this research is expansive and complex, therefore, the qualitative data analysis computer program NVivo will be used in the coding and analysis of the interviews in order to organize and catalog interview content as it relates to the emergent themes. NVivo is a program that permits the coding and analysis of textual data. The program allows researchers to develop a preliminary set of coding categories through the use of free nodes, which organize coded 
data in a way that allow the codes to evolve as themes emerge throughout analysis. NVivo will also allow us to compare and contrast interview content between women of different races and ethnicities, socioeconomic statuses, sexualities, ages, and other demographic statuses, which will be crucial in order for us to truly examine the women's narratives from an intersectional standpoint.

Each interview will be read and analyzed thoroughly, leading to the development of a set of codes based upon themes that emerge through this original read-through of the data. This coding process will be done through constant comparison analysis, through which the researcher will open code individual interviews in order to determine emergent themes and to interpret the participants' experiences. This creates a summary of each interview in the data set as well as a preliminary list of codes to move forward with. Next, the researcher will compare themes between interviews in order to create an extensive code tree that covers all relevant themes within the interviews and permits the creation of typologies or profiles. Then, the researcher will compare thematic content of interviews with women from different demographic groups in order to discern what influence these factors have on their experiences (Boeije, 2002). 


\section{CHAPTER IV: FINDINGS}

As reviewed in detail above, intersectionality explains that gender, race, class, disability, and other forms of oppression are constantly interacting to create unique life experiences for distinctive individuals (Lykke, 2010; Mehrortra, 2010; Murphy, 2009; Sandberg, 2013). With the growing number of women of color in the criminal justice system, intersectional criminology calls for a reflection on how these intersectional identities of criminalized individuals relate to their experiences (Potter, 2013). Intersectional criminological research has drawn attention to the ways in which women of color are particularly targeted due to their racial, cultural, and socioeconomic status and experiences. This current study intends to expand upon this burgeoning field of intersectional criminology by incorporating mental health into the equation. To do so, I have conducted a grounded-inspired analysis of sixty-five semi-structured life-course interviews with women on a severely mentally ill (SMI) adult probation caseload. Each of these women has been criminalized and diagnosed with a serious mental illness, so the focus of this thesis is on identifying where their experiences and paths deviated from one another by illuminating the potential role of their diverse intersectional identities.

Throughout this analysis, numerous disparities surfaced between the experiences of the White women and women of color in the current sample of criminally involved women with mental illnesses. However, not a single participant in the current sample discussed her race in any way that suggested she believed it directly impacted her experiences in the criminal justice or

mental health systems. Of the women who did expound upon the topic of race, their statements rarely involved the ways in which their race impacted them individually, but rather the racialized experiences of others. For example, Marika (White, 34, generalized anxiety) theorized that the reason she was stopped by the police in her case was because she wore a long black wig due to her 
trichotillomania which might have caused officers to racially profile her from behind. Billie (Native American, 36, bipolar) did not share any experiences of being a victim of racist behavior, but discussed feelings of distress surrounding her kids being subjected to racial bullying at school:

He's always fighting because of racial issues. He's eleven-years-old and he's already dealing with racial problems at school. My daughter, yesterday morning, I got a call from the counselor saying that a little boy had called her a [n-word] at school and he was trying to fix that situation.

While race was not overtly discussed as being an important part of these women's lives, racialized experiences and tropes, such as commonly held narratives about immigration or growing up on Native American reservations, were mentioned multiple times in the interviews. Scenarios of immigration and insinuated racialized experiences were expressed by women in the sample, some as simply fleeting comments. For instance, May (White, 45, schizophrenia), who mentioned with frustration that she had to pay the medical bills for the victim of her aggravated assault charge because "he's a foreigner and he's not even legal in this country." Betty (Black, 52, bipolar) described herself as the English-speaking minority in her workplace due to the high volume of African and Middle-Eastern immigrants employed there. Both Glinda (Native American, 34, schizophrenia) and Deana (White, 55, bipolar) disclosed the struggles of having their significant other deported to their countries of origin. While the deportation of a loved one or a criminal charge are noteworthy life events, none of these women expanded upon the racialized nature of these experiences in any substantial way.

Narratives of life on the reservation were ever-present in Billie's interview, though she never outwardly discussed her status as a Native American woman as having caused her particular difficulty in her life. In remembering her younger years, she shared memories of growing up on a reservation, which included being given drugs and alcohol freely as a young girl and being raped 
at thirteen years of age on the reservation. Later, her mother would get drunk and lost on the reservation, freezing to death before she could be found. While she did not blatantly associate these traumatic events in her life with her being Native American, they do align with tropes about the experiences of Native American women, which are marked by high levels of victimization (Bohn, 2003; Evans-Campbell et al., 2006; Rennison, 2001; Tjaden \& Thoennes, 2000) and alcohol abuse and dependency (Beals et al., 2005; Johnson \& Cameron, 2001; Yates, 1987). This gives us some insight into how her experiences of living on a reservation interacted with her gender and familial situation in a way that made her more vulnerable to victimization and thus significantly impacted her life.

Empirical evidence has consistently shown that women of color are treated disparately in every stage of the criminal justice system (Ocen, 2013). As a result, it is important to consider why women in the current sample might not find their race to be a noteworthy consideration in the discussion of their experiences. There may be three potential explanations for the universal omission of rhetoric about race in the women's life-course interviews. First, participants were not asked overtly about how their race may have impacted their specific experience, thus, they may have been less likely to discuss the subject openly during the interview. Second, there may be something unique to the twenty-two women of color who were a part of this SMI probation caseload (or women of color on SMI caseloads in general) that would make race less of an obvious barrier for them as opposed to women of color in other criminally involved samples. Third, it might also be true that the complexity of these women's intersectional identities made it difficult for them to recognize the impact of race in their experiences as they may have been more obviously affected by other aspects of their identity, including their gender, criminalization, mental health needs, or other factors interacting with their specific racial/ethnic identity. 
Expanding upon the first point of consideration, in the original data collection for the research project in which this current analysis was completed, race was not a focal point of consideration. As a result, the interviews did not contain any specific questions or prompts that explicitly concerned race or ethnicity outside of the demographic questions. The semi-structured nature of these interviews allowed the participants to have a certain level of control over what they decided to disclose, which prompted them to share deeply intimate stories and experiences in a way that they were comfortable doing. Corbin \& Morse (2003) have suggested that participants of these types of semi-structured interviews might not share vital information if they are not specifically asked about it. Given that race was not part of the general questioning of these interviews, there is a possibility that some of these women may have been aware of the impact of racial discrimination in their life but did not feel compelled to disclose that information. Additionally, the twenty-two women of color were being interviewed by a White man, which may have had an impact on what they felt comfortable discussing during their interview and how they talked about it, particularly in regard to race (a point I will return to in the discussion of limitations). Stereotype threat, social desirability, and research on race-of-interviewer effect all suggest that people of color are mindful of the power imbalances between themselves and White researchers and may feel obligated to talk about their experiences in a way that simultaneously distances them from damaging stereotypes and makes them likeable and safe from judgment (Davis \& Silver, 2003; Rhodes, 1994; Schaeffer, 1980).

The women of color interviewed had also been specifically selected to be placed on this SMI probation caseload. The discretionary nature of this process poses the question of who was deemed deserving of being placed on the caseload? Perhaps there was something about these women that not only made them "better" candidates for SMI probation, but also made them less 
likely to consider race as an important factor in their lives, or even more likely to want to participate in the interview at all.

Simply having been recognized as having a mental illness does not automatically qualify an individual for a specialty mental health caseload, as specialized units and courts are often viewed as being a privilege that is reserved for a certain type of offender who is generally more compliant and likely to be successful on probation (Wolff, Fabrikant, \& Belenko, 2011). Probationers on specialty caseloads often have to consent to that placement. This suggests that they may be more aware of their mental health problems and inclined to engage in the treatment process, comply with probation stipulations, and have positive feelings about the process. Therefore, it is fair to consider that the experiences of the women of color on this caseload are unique from those of the larger population of criminalized women of color who did not qualify or want to participate. Additionally, their mental health issues and long histories of hospitalizations and medicalization that made them candidates for SMI probation may have so significantly shaped their life experiences that they overshadowed the effects of race. The vast majority of women of color in this sample were mothers $(73.8 \%)$ with a history of substance abuse problems $(90.9 \%)$ who had been given more than one mental health diagnosis (90.9\%). It is possible that the defining experiences of discrimination of these participants' lives centered on statuses other than experiences of racial discrimination, such as their mental health, addiction, and institutionalization, and were seen as more consequential for them.

Research studies have found that racial minorities sometimes report facing discrimination based on aspects of their life unrelated to their race at a higher frequency. In a 2003 study, Minior and colleagues found that Black and Latino substance users in NYC were two to three-times more likely to report facing discrimination based on their drug use than their race. This is reflected in 
Rita's explanations of the ways she was controlled by the religious residential facility she lived in. Rita (Latina, 46, bipolar) had been sober for three years after a long and complicated history of substance abuse, but the staff at the facility prohibited her from seeing her children because they were, "Nothing but drug addicts." They also took her psychiatric medications away from her because, “...that's just like drugs," even though she recognized how important her medications were in order to alleviate her symptomology.

Researchers have also found that Black and Latino substance users were more likely to report facing discrimination based on their incarceration than their race (Minior et al., 2003). This was an evident theme in many of these women's interviews. Many expressed frustration with the difficulty they faced getting housing, government aid, and employment opportunities due to their felon status. Others felt discouraged by the way others treated and perceived them due to their criminal history. For instance, Dia (Pacific Islander, 43, schizophrenia) noted looking forward to the day she got off of probation because she hated the stigma attached to it:

I kinda feel like a bad person when I come here... I just say - I am still a good person, I go to church, I am a valuable member of society...I can still do things. I can volunteer, I can have a job. I can do stuff. It doesn't mean I am less of a human. I kinda feel like less - like I am not as much of a human. There are good people on probation.

Faith (Black, 20, bipolar) mentioned how upset she was with the way she was treated in jail, stating, "I understand that we were inmates, but that doesn't mean that I am less of a person and you are better than me in any form or way. And that is how the officers act, like you are basically a dog. Like you are basically less of a person."

The results of these studies and analyses of these narratives suggest that racial discrimination alone may not be the prevailing concern for individuals who exist at the intersection of multiple stigmatized or oppressed statuses, such as these criminalized women of color with 
mental illnesses. We must examine the complicated interactions of their multiple statuses to more fully consider their experiences and why these intersectional experiences might cause them to attribute instances of discrimination to certain parts of their identities over others.

\section{Mental Illness in Conjunction with Race}

Intersectionality argues that an individual's identity is composed of multiple statuses that place them in varying positions of privilege and oppression and that these statuses constantly interact with each other to shape their life experiences (Lykke, 2010; Mehrortra, 2010; Murphy, 2009; Sandberg, 2013). Gender and race have long been the pillars of intersectional feminist discourse, exploring the plight of women of color who suffer discrimination based not just on their race or their gender, but on the combination of the two. Scholars have since added socioeconomic status, sexuality, and physical disability to the conversation, examining the ways in which multiply stigmatized individuals navigate the world. However, there is a notable gap in the literature regarding the impact of mental illness in intersectionality and almost no research that has considered the role of intersectionality in conjunction with mental illness and crime.

The negative stigma that looms over mental illnesses and those who live with mental illnesses has been shown to have a negative impact on help-seeking (Clement et al., 2015), employment and income (Sharac, McCrone, Clement, \& Thornicroft, 2010), self-esteem, involvement with treatment, and the ways individuals are treated by society, including mental health and criminal justice professionals (Corrigan, 2004). Thus, the women of color on this caseload face not only the consequences of racism, sexism, and classism, but also those associated with their stigmatized mental illnesses and criminalization. While disparities exist in the ways that women of color in this sample were treated in the mental health and criminal justice systems compared to the White women, they never allude to their race being a cause for any disparate 
treatment. Perhaps this is a result of their mental health, substance abuse, or another defining aspect of their life being more salient in their experiences than their race. I now explore how these defining aspects of their lives have, in fact, been important in shaping their experiences by operating in conjunction with their race in order to produce these disparities.

\section{Rhetoric About Stigmatization}

More than half of the women of color on this caseload (57.1\%) described instances in which they felt mistreated as a result of their mental illnesses, exceeding the number of women of color who talked about feeling hindered and mistreated due to their criminal history or substance abuse (38.1\%) and complete absence of rhetoric about specific racial discrimination. The most common type of mental health stigmatization described by women in the current sample were instances in which they felt perceived as being stupid because of their illness. For instance, Vera (Latina, 34, schizophrenia) expressed frustration with her boyfriend's assumptions about her intelligence due to her mental illness:

My boyfriend once told me, 'You can't go to school if you're mentally ill.' He told me that one time. That hurt, you know? I think I'm fully capable, you know? 'Cause I - I mean, it doesn't mean I'm retarded, the fact that I'm mentally ill...It doesn't mean I'm stupid.

Similarly, feelings of shame and being labeled because of mental illness were themes that emerged across these interviews. Betty (Black, 52, bipolar) recalled a time when she was less open about her mental illness, "A lot of people that's on standard probation does have mental health but they don't want to let them know it...They're ashamed. I was ashamed. I was ashamed, I didn't want any people to know." Rita (Latina, 46, bipolar) looked back at her time in jail and how fellow inmates saw her, "It was awful because there was people, listening, 'Did you hear that? Did you hear that she's crazy?' It was very - I don't like it. That's an embarrassing thing for me.” Hilda 
(Latina, 30, bipolar) recounted having to grapple with her diagnosis and how it would affect her life moving forward, "I had a pretty hard awakening because I realized that I was going to have this...illness for the rest of my life and... when you're considered to be...mentally sick it's harder because people think you're crazy, so it's like, you know, you have to deal with it."

Lastly, women described experiences of stigmatization and discrimination at the hands of criminal justice and mental health professionals. Nadia (Native American, 24, PTSD) recalled jail staff refusing to provide her with her medication, which resulted in her being tased for sleep walking, a symptom of her PTSD. Billie (Native American, 36, bipolar) lamented that her sentencing judge's lack of understanding of her mental illness led to her being unfairly sentenced:

The judge, I don't think understands. I didn't speak to him about what happened, he doesn't know what happened, my story, you know?... He probably thought saw me as a monster...he doesn't know what I went through...I can't control that [her symptomology of mental illness], you know? It happens when it happens.

This stigmatization on the basis of their mental illness was a tangible experience for these women, marked for them by jail sentences, official mental health diagnoses, and stigmatizing labels. Perhaps the fact that this stigmatization was so concretely tied to that status made its impact on their lives fare more evident than experiences of discrimination and stigmatization centered around their race, gender, and socioeconomic status that may have been veiled as crime control or mental health issues.

\section{Diagnoses}

Beyond experiences of interpersonal stigmatization based upon their mental illnesses, there were concrete racial disparities in the mental health treatment of these women. The most glaring disparity between the women of color and White women in this sample in terms of mental illness was that $90.9 \%$ of the women of color, all but two, had more than one psychiatric diagnosis, 
compared to only $58.1 \%$ of White women (Table 2). Dually diagnosed women of color were most likely to have been labeled with some combination of mood and psychotic disorders (45\%), followed by combined mood and anxiety disorders $(20 \%)$, whereas dually diagnosed White women were most likely to have been labeled with either a combination of mood and anxiety disorders (24\%) or mood and personality disorders (24\%). This status of being dually-diagnosed does not exist without consequences. Researchers have suggested that it might cause clinicians to focus on each diagnosis as individual, unrelated issues, rather than a larger, complex condition, potentially leading to either the over-treatment and medication of an individual or the undertreatment of certain symptomology in lieu of focusing on others (Maj, 2005). While the White women in this sample, as a whole, were more likely to vocalize disagreement with their mental health diagnosis than women of color (23.3\% versus $18.2 \%)$, it more often had to do with their being labeled as mentally ill at all (18.6\% versus $9.1 \%)$, whereas women of color were more likely to agree with at least part of their diagnosis, but have issues with other parts of it $(9.1 \%$ versus 4.7\%). For instance, Dia (Pacific Islander, 43, schizophrenia) agreed with her diagnosis of schizophrenia, but suggested that her dissociative identity disorder diagnosis was a result of "a numb skull [mental health professional she disagreed with] who just threw that in there, you know? Just kind of stuck it on the file." Dia also expressed the feeling that she was overmedicated and did not find it to be helpful, wishing that her doctor would listen to her more regarding her mental health. Bea, (Black, 37, bipolar) stated, "Well, I know I'm depressed, um, I think I'm bipolar, but I don't think I'm schizo-whatever. I do have anxiety issues, but not that bad, because I do hear voices and everybody says I have like five different personalities, you know? But I don't know, I think it's just a lot of stress." Additionally, Silvia (Latina, 29, bipolar) and Glinda (Native 
American, 34, schizophrenia) expressed frustration at the slew of diagnoses and medications they had been handed over the course of their lives.

There was also a significant disparity in psychosis diagnoses, such as schizophrenia and schizoaffective disorder, amongst the women of color in the current study. While these women only represent $33.8 \%$ of the total sample, they represented half of those with a primary diagnosis of psychotic disorders. Additionally, while only $23.3 \%$ of the White women had a primary diagnosis of a psychotic disorder, $45.4 \%$ of the women of color did so. Research has found that, when comparing individuals involved in the mental health system, Latinx and Black Americans are diagnosed with psychotic disorders at an overall rate that is three to four-times that of White Americans, despite the fact that there has been no proven correlation between race and higher rates of psychosis (Eack, Bahorik, Newhill, Neighbors, \& Davis, 2012; Schwartz \& Blankenship, 2014). Instead, it is theorized that these disparities may be caused by wide-spread misdiagnosis, failure to acknowledge cultural differences, varying levels of access to mental health care, and clinical biases and stereotypes (Schwartz \& Blankenship, 2014), as will be discussed at greater length in the discussion section.

Given that individuals diagnosed with psychotic disorders, such as schizophrenia, are stigmatized and labeled as being dangerous and disruptive members of society (Humphreys, Johnstone, MacMillan, \& Taylor, 1992), they are at a larger risk of being controlled by the criminal justice system, the mental health system, or some combination of the two (Gosden, 2001). This stigmatization and control of schizophrenic individuals has the potential to limit their opportunities, lower their self-esteem, and hinder their treatment, recovery, and reintegration into society (Dickerson, Sommerville, Origoni, Ringel, \& Parente, 2002; Penn, Kommana, Mansfield, \& Link, 1999). This was a sentiment reflected by Pam (Black, 51, psychotic disorder), who 
reported that she was not in any type of mental health treatment and had not taken her psychiatric medications in two years because her mother was afraid of her while on them. She noted, "I was scaring my mom while I was on the medication, she said. She said I wasn't myself, I was acting weird - I was lashing out in my sleep, screaming...I didn't want to hurt my mom like that and she was getting scared of me, so I decided to get off the meds."

For Vera (Latina, 34, schizophrenia), her experiences of mental illness, homelessness, and forced hospitalization were interconnected, as she noted in her first experience of being hospitalized: "I was twenty. I was homeless and I went to them, I thought they were a shelter that had home counselors, but they turned out to be a mental hospital and they had me on medications...I never wanted to go.” This is an example of one instance in which the mental health system exerted control over a woman of color with a mental illness who lacked access to opportunities, such as employment and shelter, as a result of the difficulties associated with her mental illness. It is imperative to consider that the marginalized women on this caseload likely face significant barriers due to their higher likelihood having multiple diagnoses and of being diagnosed with specific types of mental illnesses, such as psychotic disorders, which can lend them susceptible to unfavorable circumstances that are exacerbated by their race, gender, and socioeconomic statuses.

\section{Race, Diagnosis, and Crime}

Researchers have suggested that incarceration is reserved for only the most "deviant and disturbed White women" (Warren et al., 2002), whereas women of color are more freely locked away for less serious criminal behavior (Jordan et al., 1996; Teplin et al., 1996). While the women of color and White women on this caseload were fairly similar in terms of the types of crimes they were charged with, disparities surfaced when considering race, type of crime, and psychiatric 
diagnosis (Table 3). Regardless of race, women with mood disorders were most likely to have been charged with property or financial crimes and women with anxiety disorders were most likely to have been charged with drug crimes. However, White women with psychotic disorders were most likely to have been charged with a violent crime $(60 \%$ of all White women with psychotic disorders), as was the case with May (White, 45, schizophrenia) who was charged with aggravated assault with a deadly weapon when she beat a man she was dating into a coma with a baseball bat after walking in on him molesting her daughter. After describing finding her daughter in the aftermath of the assault, she described the offense, which occurred while she was hearing voices:

Two nights later I found him where he was hiding at and I hit him in the face with a bar a couple times and then there was a baseball bat in the corner that I saw and, when he hit the ground, I just kept hitting him in the head...He was - head split open and then he went into the hospital and he was in a coma and, when he woke up, he said my name...

On the other hand, women of color with psychotic disorders were more likely to have been charged with drug crimes (50\% of all women of color with psychotic disorders), like Dia (Pacific Islander, 43, schizophrenia) who was charged with drug sales:

My mother's friend, a real old, old friend of hers, he told me - he said, 'Here,' he goes, 'I am going to give you some of these drugs to sell. You can keep the money.' He is a nice man, but he was just not good for me. he says, 'You keep the money and go give some to your mom and some to you,' and so, I asked some people...if they might be interested in buying drugs. Later, I was walking down the street and was homeless. The police stopped me...

The different types of criminal justice experiences held by women of color and White women suggest that White women who exhibit more dangerous and deviant behavior will receive punishment and treatment equal to that of similarly diagnosed nonviolent women of color. This indicates not only that women of color are more harshly punished and closely monitored than 
White women in the current sample, but also that White women must be exceptionally deviant in order to be subjected to the formal social control of the criminal justice system.

\section{Institutionalization and Medicalization}

The institutionalization of deviant women has been a favored method of social control in America (Bridges \& Beretta, 1994) that has historically been divided by race, with White women being more frequently controlled through psychiatric institutions (Brewer \& Heitzeg, 2008; Davis, 2003) and women of color being more frequently controlled through incarceration (Butler, 1997; Chesney-Lind, 1996). It is unsurprising, then, that there were significant racial disparities in the experiences that the women in this sample have had with institutionalization. The White women on this caseload who indicated having been hospitalized in their lives were more likely to indicate that it had been against their will than the women of color $(93.3 \%$ versus $78.6 \%)$, many of whom described experiences of being first institutionalized as young children, as was the case with Maria (White, 50, schizophrenia), who shared memories of a childhood spent in and out of institutions from age five for being an "unruly child."

The majority of the White women who shared memories of being involuntarily committed described their circumstances as being a result of self-harming, eating disorders, and suicide attempts (53.6\% versus $9.1 \%$ of involuntarily committed women of color). For example, Olive (White, 48, bipolar), who spent time in several different in-patient treatment facilities for alcohol abuse, suicide attempts, and eating disorders, described one particular situation in her mid-twenties in which she was committed:

I laugh at it and smile at it, now, when I think back, but I was drunk and emaciated. I had the money. I went to a hotel and got naked and stood on the balcony and said I was going to kill myself... The construction workers there called management and said, 'There's a crazy woman on the balcony over there,' and they came and got me...that's what I went into the hospital for... 
Women of color in the current sample, however, were far more likely to describe instances of involuntary commitment by court-order or police discretion (36.4\% versus $14.2 \%)$, like Billie (Native American, 36, bipolar), who listed off the reasons behind her six hospitalizations, "I was hospitalized...through the courts before. They released me to $<$ name of hospital $>$ and then I went to mental health court...I was hospitalized a whole bunch of times. Um, once the police took me to the hospital. Twice!" These differing narratives of how the participants were brought into psychiatric hospitals illuminate how White women and women of color experience controlling mechanisms that differ based on their race. White women are commonly stereotyped as weak and helpless girls who need to be protected (Glick \& Fiske, 1996; McMahon \& Kahn, 2015), as reflected in Olive's (White, 48, bipolar) recollection of but one of her hospitalizations:

I was drunk and I tried to cut my wrist and, fortunately, I called a friend who worked for a suicide hotline - and I called her up and I said, "... how long does it take to bleed to death?' And that was... a red flag right there to her and she said, 'Let me ask my supervisor.' She wasn't asking any supervisor, she was calling her parents to come and get me. And it happened... and they put me into their hospital for thirty days for that.

INT: When you tried to kill yourself... was there a reason why?

I think I was just very lonely and insecure, then. Probably still am...I wasn't where I wanted to be. I guess I wanted be, you know, prettier and thinner, obviously I had a problem there, too, and more popular. I probably just broke up with a boyfriend. I don't remember.

Unlike White women, women of color are commonly stereotyped as being hostile and antagonistic girls who need to be punished and controlled (Glick \& Fiske, 1996; McMahon \& Kahn, 2015). This was the case for Bea (Black, 37, bipolar), whose experience was a stark contrast to that of Olive's time at a psychiatric hospital, in which she was hospitalized following a suicide attempt and ended up being put on probation. Although Bea's behavior was more violent than that 
of Olive's, she indicated that it was related to her mental illness. However, that behavior was criminalized, rather than treated as a psychiatric issue:

I popped some pills, but they took me to some hospital...where they had to pump my stomach and they was gonna put me in the psych room or whatever up on the floor, but I guess I blacked out and beat them up. I beat up the doctors, the police, and they put me on probation for three years and aggravated assault.

In support of previous research, White women in this sample were more likely to be forcibly hospitalized when they displayed behaviors that threatened their physical well-being, which warranted control under the pretense of protection, and that women of color were more likely to be forcibly hospitalized when they displayed deviant, criminalized behavior, which warranted control under the pretense of punishment.

In a testament to the ways in which White women tend to be harshly punished for deviating from prescribed gender norms of passivity, obedience, and pleasantness (Kruttschnitt \& Savolainen, 2009), many of the White women in this sample, such as Maria (50, schizophrenia), Stacy (36, bipolar), Tina (23, bipolar), and Hana (20, bipolar) reflected on being institutionalized by family members for being "incorrigible," "unruly," lashing out, or having temper tantrums as young girls (5-, 13-, 10-, and 18-years-old, respectively). The women of color were more likely to be institutionalized by family members due to their concern for their decompensating mental health. Hilda (Latina, 30, bipolar) was hospitalized by her mother who expressed concern that she was unable to care for herself and Vera (Latina, 34, schizophrenia) was hospitalized multiple times by her grandfather and boyfriend as a reaction to her failing to take her medications, stating, "I never wanted to go because they - the second time they arrested me into it. I didn't want to go to the hospital, but my grandpa kept thinking I was mentally ill. I guess maybe I am.” 
Finally, women of color were more likely to emphatically state that they had never been hospitalized (22.7\%) than were White women (7\%) in this sample, like Hope (Black, 36, bipolar) who said the following when asked if she had ever spent time in a psychiatric hospital:

I refuse to go there. They've tried to get me to go.

INT: Why did you refuse?

Scared. I'm not going there. I might not come out the same person. I'm not doing it, nuh uh...I won't.

The disparate psychiatric treatment of women of color compared to White women also extended to medicating practices in the current sample. Research has shown that incarcerated women are between two- and ten-times more likely to be medicated than incarcerated men (Shaw, 1983). This forced treatment of criminalized individuals with mental illnesses is a common occurrence (Nawka et al., 2013; Sanguineti, Samuel, Schwartz, \& Robeson, 1996), one that was reflected in the narratives of many of these women, though there were some differences between the circumstances of forcibly medicated White women and women of color. While the White women on this caseload were only slightly more likely to indicate being medicated ( $93 \%$ versus $86.4 \%$ ), the medicated women of color were almost twice as likely to share experiences of being forcibly medicated in their lifetime ( $42.1 \%$ versus $20.0 \%)$. Many of these women were required to comply with their psychiatric medications as a court-order or stipulation of their probation, others described experiences of being medicated against their will while incarcerated or hospitalized, such as Billie (Native American, 36, bipolar), who recalled the complications being medicated while in jail:

It's always bad in jail...I was court-ordered to take medicine when I was in jail 'cause I was just out there. The judge and everybody knew that I wasn't competent, I had to go to competency hearings and stuff, it's harder when you have mental problems and you go to jail. You have to sit there longer than a normal person that 
doesn't have these problems because, when I go to jail, I have to sit there and wait for them to see that I'm competent. If not, I have to wait longer and take medicine and then they check on me to see, 'Oh, yeah, now she's competent to stand trial.'

The White women on this caseload were also considerably more likely to hold positive attitudes about being medicated (74.4\%) than were the women of color (54.5\%). Those who were optimistic about medication sometimes expressed frustration with side-effects or difficulty of access, like Gina (White, 48, schizophrenia), who acknowledged how important being on her medication was, but described the difficulty she faced in getting them:

I just got on my meds again because I had some problems getting [state issued Medicaid] and I was getting meds and then the doctor gave me some that was $\$ 100$ and I didn't have it. A couple months later, I finally got them to pay for it...And I didn't know whether I could go back and, when I did, the doctor said I wasn't taking my meds. It wasn't that, it was...I'm not doing it on purpose...They won't pay. They won't give me nothing.

Even still, many White women described their medication as being a critical factor in their well-being and helpful in alleviating their symptoms, like Kassie (White, 55, bipolar), who noted weight gain as a negative side-effect of her medication, but continued to take it anyway, noting its value when she stated, "The problem - this is what I had to measure. Does it matter if I'm heavy or does it matter if I'm sane? And at 55, as long as I don't get too heavy...I'm pretty overweight for me...but the medication does that job that keeps me off meth."

The allusions to frustration with side-effects and difficulty obtaining medication were also present in the narratives of the women of color who were less favorable of being medicated. Other common explanations for why they had negative feelings towards medication were that they found them to be ineffective, resented their associated stigma, and felt distrustful toward their prescribing doctors, like Silvia (Latina, 29, bipolar):

I try to take it every day. Most of the time. But that sucks because I have to take it every day for it to work. Most of the time it's not doing enough, I believe. And I 
can't help it...I have always been against the medication and never really used to -

I never really took it until...five years ago. I felt like it made me more crazy.

Faith (Black, 20, bipolar) recalled a time at which she felt overly medicated and said the following when asked if she was still on those medications:

No. I refuse to take anything that I took back then.

INT: Do you take any medications now?

No, I don't take any...because when they gave it to me, they gave me so that I honestly feel like a zombie. I actually had no brain, so I'm not trying to be like that. I have things to do, obligations that I have to do in a day.

In each of these examples, the complex ways in which race may interact with mental illness within the life-course experiences of these criminalized women is made evident when considering their narrative contemplations regarding different life experiences in context of their race. Given that they only had access to their own lived experiences, they would have had no way to compare their treatment to that of other women on the caseload. Therefore, they may have been inclined to attribute their struggles to the identity that has been most salient throughout their experiences of being controlled, their mental illness, without consideration for the ways in which their race, gender, and socioeconomic status, among other things, may have interacted with that mental illness and molded their paths in a way that significantly differed from those of others.

\section{Intersectional Identities Shaped through Power and Control}

Intersectionality, in its essence, argues that an individual's identity is comprised of many different statuses that continuously interact with each other to shape the ways in which they experience the world (Lykke, 2010; Mehrortra, 2010; Murphy, 2009; Sandberg, 2013). These statuses are socially constructed and managed through complex systems of power and control, creating imbalances of privilege and oppression. The exertion of this power and control over 
individuals most apparently manifests itself in the variant ways in which differently labeled individuals experience significant, defining life events. With the growing number of individuals with mental illnesses, women, people of color, and those whose identities intersect all three of those statuses, in the criminal justice system, intersectional criminology calls for a reflection on how the intersectional identities of criminalized individuals relate to not only the variations in their defining life experiences, but in the ways these experiences shape their own perceptions of themselves (Potter, 2013). For the women in this current thesis, these defining life experiences were often surrounding profoundly personal and emotional aspects of their life, such as abuse, addiction, and sex work, which deeply permeated other parts of their lives and influenced the ways in which they formed and spoke about their identities.

\section{Experiences of Abuse}

Histories of abuse amongst offenders is a widely explored topic of criminology, with many theories centering on the high rates of victimization amongst criminalized women (Turanovic \& Pratt, 2013). These high rates of victimization were ever-present in the narratives of current sample, with many directly relating their experiences of abuse to their mental health issues, substance abuse issues, and criminalization. The nature of abuse endured varied drastically across each narrative in terms of intensity, duration, and relationships with abusers. Nearly three quarters (73.8\%) of the sample indicated that they had been victims of physical, sexual, and/or emotional abuse in their lives, often times in conjunction with one another. They most commonly cited instances of physical abuse (58.0\% of White women, $45.5 \%$ of women of color), followed by sexual abuse (46.5\% of White women, $40.9 \%$ of women of color), and then emotional abuse (34.9\% of White women, $9.1 \%$ of women of color). 
Physical abuse. Physical abuse was reported by over one-half (53.8\%) of all participants. Of those who indicated being physically abused in their lives, women of color and White women were fairly equally likely to have experienced childhood physical abuse as they were to experience physical abuse in their adult lives. However, racial discrepancies began to surface when analyzing the perpetrators of this abuse. White women most often reported being physically abused at the hands of their parents or step-parents, whereas women of color were most likely to report being physically abused by other family members or family friends (such as siblings, babysitters, aunts and uncles, or their mothers' boyfriends) or by their romantic partners, with only one-third reporting being physically abused by their own parents.

The White women who shared instances of parental physical abuse often described it in conjunction with parental sexual abuse, such as Tina (White, 23, bipolar), who shared the following:

My dad...molested me and beat me and I was the favorite one to hit. I had two sisters and, out of all three of us, I was the only one he molested, but he used to beat the crap out of all of us, he really would. He used to beat us and choke us and just do weird things, but he would molest me for some reason.

Others believed that the physical abuse they endured at the hands of their parents stemmed from likening them to their other parent, like Jenna (White, 35, bipolar), whose mother and stepfather beat her as a child:

She was very abusive. All she wanted to do was beat the crap out of me because she didn't want me to be alive in the first place because I was female. She only wanted males and I was her punching bag...

The two women of color who experienced physical abuse at the hands of their parents did not share these experiences, but instead explained it as a consequence of their parents' substance 
abuse issues, as was the case with Rita (Latina, 46, bipolar), whose mother was a severe alcoholic with a history of suicide attempts:

I always got beat from my mom, constantly, I was beat down every day. I couldn't even get a little spot on my pants 'cause she would beat me...Plus I couldn't have boyfriends. If I did, my mom would be waiting outside with a belt. When he would drop me off...she would pull me from my hair, didn't care who was right there, and she would start hitting me with the belt...She was always drunk. She was an alcoholic, but so was my dad.

Glinda (Native American, 34, schizophrenia) also tied her parents' being alcoholics to her victimization, “...My mom was too busy going out, she drank a lot, so did my dad and my dad was never there. He left when we were little...They were alcoholics...My mom used to always hit us because we were my dad's kids."

Much more common among the women of color were situations of being physically abused by their romantic partners. Rita (Latina, 46, bipolar) described a particularly volatile relationship with her children's father:

I got screws on my right ankle, I broke my shoulder, broke my jaw, he broke my nose, I got scars all over my head where he beat me. He used to kick me down with steel-toe boots. I was never a day without a black eye or a busted lip, you know? ... My kids heard everything. My kids seen him beating me, one time, so bad that he was kicking me with his steel-toe boots and at the same time ripping my clothes...by the time he finished, I couldn't even move. And the next day I was completely bruised up.

The impact of these physically abusive romantic relationships on the mental health of these women was evident across their narratives, as was the case with Bea (Black, 37, bipolar), who described a situation that ended with her in a psychiatric hospital as being a result of her baby's father's abuse:

I blacked out and... beat up some people and woke up and I was in the crazy house with a white jacket on, you know? They was like, 'You need help.'...I was threatening to kill my baby's daddy and myself because he is abusive, too. It was either kill him or be killed...I just got tired of it... 
Erika (White, 41, bipolar) was one of several women who recalled suicide attempts that were direct results of abuse they experienced at the hands of their partners:

...He got all my pills and he sat them on the floor and he said, 'I'm going to leave.' It was like one o'clock in the morning and I couldn't even move. He'd ripped most of my hair out and hit my head against the wall and that was the worst time he'd ever beat me. And he got a big ol' jug of water and said, 'I'm going to leave for two hours. Just take all these pills and kill yourself to make the world a better place.'

It is evident that experiences of being physically abused was deeply traumatizing for all of these women, regardless of race. However, the racial disparities present in regard to the nature and perpetrators of that violence indicate that we cannot lump together victims of abuse into one category. Instead, we need to focus on how intersections of race, gender, and mental illness impact the interpersonal relationships of these women of color in a way that made them more vulnerable to violent victimization at the hands of their romantic partners and extended family than the White women in this sample.

Sexual abuse. Researchers have found that children raised in nuclear families (i.e., raised by both their biological mother and father) are significantly less likely to be victims of sexual abuse (Bolen, 1998). However, people of color experience life in a Eurocentric society in a complicated and unique way that less often adheres to this "nuclear" standard. Immigration (Baca Zinn \& Wells, 1999), cultural emphases on kinship and collectivism (Baca Zinn \& Wells, 1999), poverty, low marriage rates (Abney \& Priest, 1995), and the criminalization of people of color (Taylor, 1999), among other things, have interacted to shape the family structures of people of color in a unique way, creating a larger number of multi-family households, single-parent households, and other non-traditional familial situations (U.S. Census Bureau, 2002). These variations in family structures are but one example of the way in which intersectional identities and experiences shape 
the lives of individuals in a way that might predispose them to experiencing life events in different ways.

Many women of color in the current sample cited these non-traditional family structures as being beneficial parts of their lives, as was the case with Dia (Pacific Islander, 43, schizophrenia), whose adoption by her grandparents at six days old due to her mom's heroin addiction was a positive thing for her:

I had an ideal, perfect childhood living with them and good role models and good structure, you know? But then I had to go live with my mom after my grandmother died, passed away, and I had to go live with my mom and she had a boyfriend and she had just gotten off heroin and tried to get me on it. I just kind of fell apart right then.

Betty (Black, 52, bipolar) also described the ways in which different generations of her family took on the responsibility of helping raise each other's children or supporting each other when needed. This ranged from her helping to raise her siblings as a child, "I was the oldest child, so I carried a lot of weight, a lot of weight. And I took care of my sister and my brother at a young age, and it's just my mother and father were middle class trying to work all the time, so I took on a lot of responsibility," to her parents helping her raise her own children, and finally to her current mutually supportive situation with her children, wherein they helped watch her children while she was incarcerated and now, "I watch my grandson, that's what keeps me going, watching my grandson...I depend on my kids [financially], and I shouldn't depend on 'em, you know?" She also noted, "I got my sister off the street, so she's living with me now, her and her kids." Betty and Dia's situations were examples of the ways that families of color successfully managed financial and child-rearing difficulties by deviating from the nuclear family structures idealized by White American culture. 
However, these expansive family systems could also potentially account for the disparate number of women of color on this caseload who reported being victimized by extended kin, such as uncles, babysitters, family friends, mom's boyfriends and his kids, etc. (88.9\%), compared to White women (40.0\%), who are more likely to be raised in a nuclear family situation and perhaps have less contact with these extended kin.

For Billie (Native American, 36, PTSD), her abuse at the hands of her uncles as a young girl living on the reservation appeared to be a result of the absence of her alcoholic mother and her subsequent dependence on her more extended family and community to care for her:

I grew up here and there. My mom was an alcoholic and all she cared about was drinking and running away with her friends, so I never really saw her. I spent most of my childhood looking for her, you know? Asking people, 'Can you please take me over here and take me over there, look for my mom?' You know? I grew up like that and I was molested and abused and stuff like that by other people... it was my aunts' husbands. It was always my aunts' husbands.

Raquel (Black, 26, bipolar) was one of several women on this caseload who reported being raised by her grandparents. In her situation, it was due to her biological parents' drug addictions and cycling in and out of prison. While Dia (above) described these circumstances as being beneficial in her situation, Raquel had a different experience. She only vaguely noted that she endured physical and sexual abuse from a "family member" while in their custody but did not go on to specify the nature of their relationship.

While White women commonly reported being sexually abused by their step-fathers or biological fathers, only two women of color did, both seemingly as a consequence of absent or abusive mothers, such as Rita (Latina, 46, bipolar), who was physically abused by her mother and described both of her parents as alcoholics. She reported being molested by her father for a few months at the age of six, and speculated that her mother allowed it to happen: 
When I told them what my dad was doing to me, she [her mother] beat me "cause I was supposedly lying, you know?...Then he stopped because I started telling my mom, you know?...Honestly, I think she knew because, what was weird to me, I was little and I still remember him going, 'Sit down right here on the bed,' and as soon as she would go in the shower, she would take forever, like, 'Mom, I need you,' you know?

Bea (Black, 37, bipolar) only met her mother as an adult and was raised by a single father who was persistently sexually abusive, "I was living with my dad, and I don't really call him dad, I call him a sperm donor. He raped me from eight to fifteen and then he kicked me out when I was fifteen "cause I got raped by six guys and he said I gave away his pussy."

Several women shared that they had to engage in survival behaviors that have been deemed criminal in order to protect themselves. Many of them ran away from home in order to escape ongoing sexual violence at the hands of the people they lived with, such as Amy (Black, 50, schizoaffective), whose mother's boyfriend was sexually abusing her, but feared to tell anyone, "I was too scared, he told me he'd kill me and my family if I said anything. That wasn't so good...And so, I started running away from home when I was...thirteen. Ever since I was thirteen, I'd run away from home and my mom sent the police and stopped it." Glinda (Native American, 34, schizophrenia) also explained that one of her mom's boyfriends abused her physically and sexually as a child, which was why she ran away from home at 13-years-old, "I never went back there...I thought it was just better and why would I want to be where he was? So, I thought it was better to be out on the streets." Hana (White, 20, bipolar) was also physically and sexually abused by her step-father, describing a childhood marked by violence, "I defended myself a lot when I was younger. Pushed him into walls, knocked him out for three days, you know? Stuff like that. Because I had to protect myself and all I remember is violence with my family." Her efforts to 
protect herself led to her running away at the age of twelve, and act of self-preservation that ended up propelling her into the criminal justice system. She explained:

The cops came and got me from a friend's house, I ran to a friend's house...her mom called the police and...the cops came and saw that I was bruised from head to toe, real dark, and was so bruised that my bones were crippled pretty much so that I couldn't even move my body. So, they put me in a detention center for thirty days and said, 'You have to find a safe home and if you don't find a safe home, we have the rights to take you to CPS,'

Furthermore, it was common for these women to relate their sexual abuse to their mental health issues. Some more flippantly, such as Nadia (Native American, 24, PTSD), who was physically and sexually abused as a child by family members and her mom's boyfriend. Yet, when asked how she would describe her childhood, she simply laughed and stated, "Probably the reason why I have post-traumatic stress." Others were too distressed to discuss their traumatic memories of victimization, such as Pam (Black, 51, psychotic disorder), an otherwise bright and forthcoming participant whose demeanor shifted dramatically when asked about her childhood. All she managed to say about it was, "Um...it was okay. It was kind of bad."

Several participants more concretely tied together their victimization and their later mental health issues, such as Reva (White, 34, PTSD), who was raped as a teenager, resulting in a son. She speculated that the stress of being a young mother recovering from sexual assault caused her mental break.

I became a mother at fifteen and being a mom at that young age and my son being a rape baby, it was hard for me to deal with, but I couldn't give him up. I decided to raise him and take care of him, and doing all of that and trying to go to school, you know...It was hard...I was pretty confident I got overwhelmed...I was going to blow a gasket because I was - like, everything all at once just caught up, and I knew it was a bad thing, you know?

Billie (Native American, 36, bipolar) was molested by her uncles as a toddler, but cited the trauma of being raped on the reservation at 13-years-old as being the trigger for her mental illness. 
She explained that it did not appear to affect her until she finally told someone else about the event at 21-years-old:

I didn't tell my friends, nobody. So, one day, I was talking to my friend, [redacted], she's my best friend, and I was talking to her about it and I brought it up. I said it. And that's when my mind just went crazy. I actually talked about it and as soon as I talked about it, my whole body just went weak and it just seemed like this black thing, this shadow, left my body and I saw things different. Like the sun was shining, I felt like a little kid, you know? I felt like a little kid...And a few days later, these voices came and, oh my god, I couldn't shower, I couldn't... They were like yelling, screaming, malicious things, you know?

While almost one half (44.6\%) of this sample indicated having been sexually abused in their lives, the varying types of victimization and levels of access to support and treatment rooted in the social positions of their intersectional identities impacted the ways in which they processed that trauma. As a result of their disadvantaged positions in society due to the interactions of their mental illness, socioeconomic status, gender, and race, many of these women lacked the social support systems and financial means to healthily manage their traumas and were driven to find solace in other coping mechanisms, such as drugs and alcohol.

\section{Experiences of Addiction}

Over $81 \%$ of the women interviewed in the current thesis indicated that substance abuse was a significant part of their life, with women of color being most likely to have had substance abuse issues (90.9\% versus $76.7 \%$ of White women). While some women chose not to disclose the motivations behind their substance abuse issues, those who did most often described attempts to self-medicate ( $54.7 \%$ of drug users in sample). This was most prevalent in the interviews with the White women, with two-thirds (66.6\%) of White drug users alluding to the use of drugs and alcohol to alleviate physical ailments, mental health symptoms, and emotional traumas, compared to just over one-third of the women of color (35.0\%). 
Roughly one-quarter (24.1\%) of those who indicated some level of self-medicating drug use described doing so in an attempt to deal with physical ailments ranging from Lyme's disease to cancer to chronic back pain. Almost all of these women also shared histories of more tumultuous relationships with substance abuse. For instance, while Olivia (White, 50, schizophrenia) explained her meth use as a way in which she coped with the pains of her cancer because it provided her "an escape - a recharge..." that allowed her to be more productive, she also shared a history of using crack cocaine since the age of fourteen and, later, a "marriage of convenience" in which she was actively using drugs and married a drug dealer. Joan (White, 54, bipolar) also recalled a period in the eighties in which she often used cocaine recreationally, but explained that, nowadays, she only smoked marijuana to alleviate the pains she endured as a result of her Lyme's disease.

The remaining three-quarters (75.9\%) of women who indicated substance abuse as a form of self-medication did so because it either helped to directly alleviate the symptoms of their mental illnesses or made it easier for them to cope with traumatic experiences, such as childhood abuse. Dia (Pacific Islander, 43, schizophrenia) described a long period of time in her life in which she was badly addicted to alcohol, "It helped me drown out some of the voices, some of the... I was self-medicating back then. I was getting real sick.” Kassie (White, 55, bipolar) described her addiction as being related directly to her mental health:

They are associated with each other. I used to get real manic and then, if I did meth, I would calm down, so it was a cycle. I would take medication, my psych medication, then I felt better, stop taking psych medication, go on to manic, use, and then put in the hospital and start over again.

Several women explained that their first experiences of substance abuse were facilitated by parents or partners. Alex (White, 31, bipolar) shared memories of doing drugs and drinking with 
her mom as a young girl, which led to a lifetime of battling addiction when she noted, "I was a bad alcoholic when I was like thirteen, fourteen...that was bad. And then I started doing coke, and sold coke for a long time, and then I found G [meth] and I started doing that crap and it just took my life down, you know?"

The greatest discrepancy between the White women and women of color in the current sample in regard to substance abuse was that women of color were far less likely to attribute their substance use to self-medicating than were White women (33.3\% versus $65 \%)$. Instead, they were more likely to describe their introduction to drugs as being social or recreational activity, like Hilda (Latina, 30, bipolar), who explained the onset of her crystal meth use when she stated, "It started by hanging out with my friends and going out to the clubs and stuff, and then, we just started experimenting with drugs... Somebody introduced us to the drug and then we started doing it and it was just, you know, part of my life for a while." Many others chose not to elaborate on their experiences with substance abuse, like Bri (Black, 45, schizophrenia), a participant charged with possession and paraphernalia, who, when asked if she had ever used or been addicted to drugs, simply said, "Years ago, not now...To alcohol. That was bad." The racial disparities in how these women described their experiences of substance abuse may reflect how White women and women of color might differently present their experiences with substance abuse because of their positions in society.

Kerrison (2015) theorized that systems of privilege allow White drug addicts to construct their experiences with drugs and addictions in a way that frees them from true culpability. By rejecting the "ineluctably criminal persona assigned to Black addicts, White users may instead claim their victimhood, illness, and eschew accountability" (Kerrison, 2015, p. 105). This denial of accountability was present in several interviews with White women in the current sample with 
substance abuse issues, such as Stacy (36, bipolar), who attributed her addiction to genetics, a notion that was not present in any of the interviews with the women of color. Stacy stated, "It's in my family. My mom was an alcoholic and an opiate abuser, she abused heroin. So, it's in my bloodline, it's in my genes, and also it got introduced to me when I was young, so I inherited it." Kerrison's (2015) exploration into these divergent self-assessments of addiction focused on the how the medicalization of addiction has proven to be largely beneficial for White addicts, whereas people of color are only further penalized. Rather than risk the further loss of autonomy associated with an admission of illness and a potentially accelerated route into the controlling grasps of the mental health and criminal justice systems, people of color might try to present their

substance use as less severe or unrelated to any mental health issues (Kerrison, 2015). Additionally, Kerrison (2015) suggested that people of color who live in impoverished, "hostile" communities might feel the need to reject or conceal notions of mental illness in association to their substance abuse so that they do not appear to be vulnerable or weak members of a community in which they have to fight to survive.

\section{Experiences of Sex Work}

Sex work, such as prostitution and exotic dancing, has historically been a means through which otherwise disadvantaged individuals are able to earn an income. About one-fifth (18.5\%) of the women analyzed for this thesis disclosed that they had participated in sex work at some point in their lives. While the women of color and White women engaged in sex work at similar rates, the nature of that engagement was more disparate, with White women equally as likely to indicate that their experiences in sex work were voluntary $(50 \%)$ as they were to indicate that they felt either coerced into it or that they had no other options (50\%). Whereas women of color were more 
likely to share experiences of coercion or desperation in regard to their experiences of sex work $(75 \%)$ than they were to indicate that it was voluntary $(25 \%)$.

The women who indicated being voluntarily involved in sex work described it as a generally positive experience, with most only "retiring" because they were forced to in some capacity. For instance, Sally (White, 49, bipolar) looked back fondly on her career as an exotic dancer, "I loved being on stage." She even continued to dance following being hit by a drunk driver and losing one of her legs, but finally quit after, "I got married and he didn't want me to dance..." Similarly, Marnie (White, 28, anxiety disorder) regarded her time as a dancer and cocktail waitress in a positive light, but lamented the fact she could no longer do it, stating that she enjoyed working, “...especially the [jobs] I was making the most money at, like dancing stuff. They don't let me do any of that, so..." She noted how broke she was after being made to quit by her probation officer, wishing she could go back. Jenna (White, 35, bipolar) worked as an escort and described that part of her life as enjoyable learning experience:

I did it, not because of the simple fact that I like the job, but because I was trying to figure out what relationships guys like, don't like, what they like doing, what they don't like doing. It was my experience to figure them out...And I experienced different stuff with me, you know? Who they are, and what they are, and what not to do, what to do, you know? I'm a curious person.

While the aforementioned women participated in the sex industry of their own volition, other women explained that their entrance into sex work was necessary in order to support themselves and their families. Researchers have described this type of sex work as an inherently "gendered survival strategy" (Farley, Lynn, \& Cotton, 2005, p. 243) implemented by disadvantaged women. This use of sex work as a gendered survival strategy is significantly higher amongst the women of color in this study because they face exceptional difficulty in accessing 
opportunities such as education, housing, and stable employment due to their intersectional experiences.

While one woman disclosed that she had been pimped out by an ex-husband, most women described getting involved in sex work because they had no other way to survive, such as Amy (Black, 50, schizoaffective), who, in describing a criminal history that included prostitution, trespassing, and shoplifting, explained that she was simply trying to survive the twenty years she spent living on the streets:

I met the wrong people on the streets and they would teach me some of their wicked ways and, before you know it, I'm doing the same thing they're doing.

INT: What kind of things have you been arrested for?

Oh, prostitution, drugs, arson...trespassing, shoplifting...Yeah. I even went into a store and stole some salami, some lunch meat, 'cause I was so hungry.

INT: So, how long did you live on the streets like this?

I've been on the streets, man, for like twenty years...I've been a prostitute, and God wants me to go to the people... he said he was going to give me a street ministry once I straightened up...I got the calling, so God's going to make something good out of something that was very bad.

The women also engaged in sex work to access other opportunities that they would have been unable to achieve otherwise, such as an education, as was the case of Nadia (Native American, 24, PTSD) who did not enjoy her job as an exotic dancer, but did it because it helped pay for her education when she felt less able to work other jobs:

I was paying my way through school, paying my bills, anything, you know? It was better than, like, working with a kid, being stressed out, or working with a cook and standing on my feet from 3 in the morning. I used to stand from $3 \mathrm{am}$ to $4 \mathrm{pm}$, get off, and go to school. Stay there until $11 \mathrm{pm}$, and then have to wake back up, get home by 12 , go to bed by 1 , then get back up in 2 hours. 
Similarly, Hota (Latina, 27, schizophrenia), cited the need for transportation as a reason for why she participated in sex work, as she depended on prostitution in order to get around the city, “I wasn't even trying to make money, I was just trying to get a ride to go to the store, you know? I was just trying to buy some things and get back to my hotel."

Although White women and women of color in this sample were fairly equally likely to disclose that they had participated in sex work, their personal narratives about those experiences, and the reasons for engaging in those experiences, made it evident that their motivations to engage in that sex work and their feelings about it differed. The inclination to treat all sex workers in the criminal justice system the same fails to acknowledge how critical the interactions of race, gender, and socioeconomic status are on the ways these women enter and experience sex work. If the primary goal of law enforcement and criminal justice is crime prevention (Tonry \& Farrington, 1995), it stands that the treatment of criminal offenses should be implemented in a way that addresses the underlying problem and aims to resolve it. However, the failure to consider sex work, among other crimes, through an intersectional lens simply punishes a behavior without addressing the over-arching institutional mechanisms of control that shaped the experiences. 


\section{CHAPTER V: DISCUSSION}

Intersectionality is an examination of the socially constructed statuses people hold and the associated privileges or disadvantages of the combination of those lived identities. Privilege and oppression do not operate in a void. They interact with each other in a structural way wherein the oppression of one group operates to sustain another's privilege and vice versa (Neville, Worthington, \& Spanierman, 2001). The findings of this thesis revealed the presence of these varying levels of privilege and disadvantage in the disparate life experiences across the narratives of the women in the current sample - a group of 65 criminally involved women all living with significant mental illness. Results demonstrated that, compared to the White women in this sample, women of color were more likely to be diagnosed with psychotic disorders and to be dually diagnosed, were less likely to indicate being involuntarily committed, but far more likely to be hospitalized by police or court-order, were more likely to have been forcibly medicated and have negative feelings about psychiatric medication, were more likely to discuss experiences of substance abuse but less likely to attribute that abuse to their mental illness, and were more likely to have felt coerced to engage in sex work than to have wanted to do so. Yet, despite the evidence of these numerous racial disparities in their life experiences, not one participant suggested that her race impacted the way she was treated in the criminal justice or mental health systems. This poses the question of whether race, alone, had an impact on these women's experiences, or if race played a more nuanced role when operating in conjunction with other facets of their identities, specifically mental illness, socioeconomic status, criminalization, or life-course circumstances.

\section{Illuminating Intersectionality}

Socially constructed institutions of oppression, such as racism and sexism, permeate all spheres of social life, but they can be easily obscured by singular aspects of one's identity that are 
more saliently tied into their marginalization. For the women in the current thesis, oftentimes the piece of their identity interacting with race most appeared to be their mental illness. It was easy for many of these women to recognize the detrimental effect that having a mental illness had on their lives, having been repeatedly medicalized, hospitalized, and criminalized for circumstances that surrounded their diagnoses. Criminalization and addiction were two other parts of their identities that impacted their lives in a way that was easily established from narratives intrinsically tied to those identities, such as incarceration or rehab.

While modern society condemns discrimination on the basis of gender and race, scholars have suggested that discrimination has a way of evolving to operate successfully in ever-changing geopolitical climates, a process referred to as, "preservation through transformation" (Alexander, 2010; Siegal, 1997). Alexander (2010) explained that current policies regarding crime facilitate the subjugation of vulnerable populations under the guise of protection and crime control. Heavy emphases on the importance of managing deviance and protecting the community work insidiously to place the blame for these societal problems on marginalized individuals in order to prevent potential accusations of discrimination based on other parts of their identities.

It is natural to simplify and disguise the hardships of the women in this sample in terms of just their criminal behavior or their mental illness rather than truly delve into complicated interactions of their identities and experiences and their positions in society. In fact, the covert forms of control that may produce the disparities in these women's narratives have been so heavily cloaked under crime control and mental health treatment that they might be unrecognizable to them in the course of their daily lives. However, the over-simplification of these complex issues negates any genuine understanding in a way that continues to prevent us from fostering authentic equality, not only in this sample, but for all populations existing in complex systems of intersectional 
identities. The first step in combatting this is the universal implementation of intersectionality into all future research. Intersectionality is a complicated subject and necessitates an intricate fusion of intensive qualitative and quantitative research methods, but this challenge is one worth taking.

\section{Changing Policy}

\section{Addressing Abuse}

Histories of abuse amongst offenders is a widely explored topic of criminology, with many theories centering on the high rates of victimization amongst criminalized women (Turanovic \& Pratt, 2013). These high rates of victimization were ever-present in the narratives of these sixtyfive women, with many directly relating their experiences of abuse to their mental health issues, substance abuse issues, and criminalization. However, victims of abuse are too often lumped together as a homogenous population, despite the fact that the nature of abuse endured by the women in the current sample varied drastically between White women and women of color, particularly in terms of their relationships with their abusers. The relationship between the victim and perpetrators of abuse has been proven to have an impact on the severity and duration of the abuse (Russell, 1984; 1986), coping strategies, and likelihood of developing PTSD (Cantón-Cortés \& Cantón, 2010). Therefore, it is imperative that we examine how intersections of race, gender, mental illness, and life circumstances render individuals more or less vulnerable to varying types of abuse and that we address that abuse in an equally intersectionally and culturally conscious manner.

\section{Addressing Sex Work}

Research often relates lack of opportunity and participation in sex work as being fundamentally connected to each other (Sanders, 2007). Sex work can provide money necessary for the survival of many women, like those in this current sample, who might be otherwise 
overwhelmed by the disadvantageous effects of poverty, weak social support systems, and criminal records or mental health issues that complicate access to education, stable housing, and employment (Brantley, Footer, Lim, Kerrigan, \& Sherman, 2017). However, the narratives of the handful of women in this current sample who discussed their experiences of sex work indicated that White women and women of color had diverging motivations for engaging in this behavior. The disproportionate number of women of color in this sample who resorted to sex work as a means of survival in the absence of other opportunities compared to White women who participated in this work because they enjoyed it is indicative of the ways in which race might mediate the level of autonomy a woman has over her body. Their experiences also elucidate how barriers the women of color faced in association with their gender, race, class, mental health, and criminal involvement barred their access to legitimate employment, essentially pushing them into sex work and putting them at risk for being further criminalized for that survival strategy.

The tendency to examine sex work as a deviant behavior or the desperate last resort of defeated women not only fails to acknowledge the existence of sex workers who voluntarily participate in the trade and find it to be a positive experience, but also ignores the mechanisms that drive women to feel compelled to engage sex work. The culmination of the deleterious effects of the discrimination and subjugation of intersectionally situated individuals restricts their access to opportunities afforded to more privileged individuals and forces them to find alternative means of meeting their basic needs and achieving their goals. Going forward, rather than viewing sex workers as a homogeneous population that needs saving, researchers need to acknowledge the ways in which an individual's intersectional position in society can influence a myriad of circumstances in their lives that might lead them to engage in sex work and whether that involvement is voluntary or forced. A more inclusive, intersectional examination of sex work 
would allow for the development of more culturally competent and effective proactive deterrence methods and support services that could help keep the women who do not want to engage in sex work out of it and protect those who do.

\section{Addressing Mental Health Diagnostics and Treatment}

Mental health treatment is inherently Euro-centric, which leads to people of color being incorrectly labeled and treated at alarming rates (Eack et al., 2012; Schwartz \& Blankenship, 2014). This disparate mental health treatment was reflected in the experiences of the women in this sample, with the women of color being significantly more likely to be diagnosed with psychotic disorders and forcibly medicated than the White women and the White women being most likely to be hospitalized. The presence of these variant levels of control exerted on women of different races reflects the ways in which White women who deviate from social expectations are treated with paternalistic and chivalrous actions that seek to protect them from themselves by removing them from risky situations (i.e., being hospitalized following a suicide attempt) whereas women of color who engage in similar deviant behavior will be held responsible for those actions and punished as such (i.e., being chemically pacified with psychiatric medication) (Datchi \& Ancis, 2017; Spieglman, 1977). In order to address these discrepancies, we need to construct more culturally-conscious diagnostic and treatment processes.

Neighbors and colleagues (1989) outlined two opposing schools of thoughts commonly employed to explain why there exist racial disparities in diagnostics. The first postulates that Black and White Americans present fairly similar psychiatric symptomology and that the diagnostic disparities present are formed by the stereotypes held by clinicians. In these situations, clinicians may be more inclined to collect diagnostic evidence that confirms their cultural stereotypes and hypotheses about individuals who do not fit the "dominant culture" than evidence that might refute 
them (Garb, 1997; Haverkamp, 1993, Neighbors et al., 1989; Schwartz \& Feisthamel, 2009; Thompson, 2010, p. 32). The second school of thought advances that Black and White Americans present differing psychiatric symptomology and diagnostic disparities occur because they are treated and diagnosed similarly due to the widespread use of inherently Euro-centric diagnostic tools and processes that are not informed by cultural differences and intricacies (Neighbors et al., 1989; Schwartz \& Blankenship, 2014).

Garb (1997) further maintained that Black and Latinx Americans are still more likely to be diagnosed with schizophrenia even when their symptomology does not meet the diagnostic qualifications and criteria for said diagnosis. In one 1983 study, researchers found that nearly $85 \%$ of the Black and Latinx participants of their study had been misdiagnosed as schizophrenic compared to only $51 \%$ of White participants (Mukherjee, Shukia, Woodle, Rosen, \& Olarte). Schwartz and Feisthamel (2009) suggested that these disparities might be explained by clinicians potentially regarding "disruptive or socially deviant behavior patterns" (Schwartz \& Blankenship, 2014) of Black clients when determining diagnoses. However, when examining the diagnoses of White and Black Americans in pre-trial correctional facility, Perry, Neltner, and Allen (2013) found that the White inmates were still $78 \%$ less likely to have a psychotic diagnosis than the Black inmates. One of the few circumstances in which Black patients were not disproportionately labeled as being schizophrenic is when clinicians were asked to decide whether individuals whose circumstances were identical and differed only by race were schizophrenic or suffering from druginduced psychosis (Garb, 1997). In these instances, Black patients were significantly more likely to be diagnosed with cannabis-induced psychosis and White patients were more likely to be diagnosed as schizophrenic (Lewis, Croft-Jeffreys, \& David, 1990). 
Given that the women of color in this current sample were far more likely than the White women to have a psychotic diagnosis and that that those with a psychotic diagnosis in this current sample were most likely to be forcibly hospitalized $(68.4 \%)$, be medicated overall $(95 \%)$, and forcibly medicated (42.1\%), it is important to consider how their being disproportionately labeled as having these types of disorders may have influenced their life experiences in order to make it easier for the mental health system to exert control over them.

It is evident the role that institutionalized and internalized biases have on the placement of people of color in the mental health system and how that placement can set the course for a myriad of disadvantageous experiences to come. This extends to treatment in the criminal justice system, community services, education, employment, and other vital situations in these individuals' lives. These biases do not exist in a vacuum, but are mediated and exasperated by race, gender, socioeconomic status, and a myriad of other statuses. For some of the women of color in this sample, narratives about feeling misdiagnosed or improperly treated for their mental illness were often tied into their substance abuse issues or criminalized behavior caused by their symptomology. The implementation of more intersectional and culturally conscious diagnostic and treatment practices may very well have been able to manage their mental illnesses in an effective manner that would not have forced them to rely on substances to alleviate their symptoms or to remain symptomatic and be criminalized because of related behaviors.

In order to end this disparate and marginalizing practice, researchers, practitioners, clients, and the general public alike must be cognizant of the role of intersectionality and critically examine how it interacts in the lives of the people they are attempting to help so they do not fall into the trap of essentialism by treating them based on just one caveat of their identity. They must also critically examine their own complicated positions of privilege or oppression and actively fight 
their internalized predisposition to over-treat or over-control those whose statuses differ from their own.

\section{Limitations}

\section{Generalizability}

This thesis does not claim to represent the experiences of all women. In fact, the rejection of essentialism in that way is the basis of intersectional research. While these women and their narratives presented a myriad of important examples of the role of intersectionality in the lives of marginalized women, we must consider that marginalization is not afforded just to these criminally involved women of color with mental illness, but vast amounts of other individuals who experience different variations of privilege and oppression. This current sample is composed of sixty-five women who are part of a specific caseload in a specific region because of their unique experiences of crime and mental illness. Therefore, we cannot attempt to equate our discoveries in this thesis to those that might be found in other diverse populations. We can, however, learn from the complicated ways in which intersectionally defined the identities and life experiences of these women and how they perceived and spoke about those things and attempt to examine other groups of marginalized people through that lens in order to determine commonalities and discrepancies in their experiences.

A wide-spread application of intersectional theorizing in criminology cannot occur if research focuses solely on these ungeneralizable populations without working towards a more generalizable, theoretical framework. Instead, researchers should strive towards more comprehensive samples (e.g., the inclusion of control participants and a comprehensive assortment of individuals of variant gender identities, sexual orientations, races and ethnicities, socioeconomic statuses, criminal histories, mental health backgrounds, etc.) in order to be able to develop 
significant and inclusive hypotheses about the role of intersectionality in criminology. While we will never be able prescribe a specific experience of intersectionality to someone based on their social location, as each person will internalize and negotiate their life experiences in unique ways, we can at least begin to hone in on and conceptualize the application of intersectionality to the lives and experiences of criminalized individuals.

\section{Truth in Narrative}

Intersectional identities place individuals in varying positions of social power or subordination in relation to each other in ways that shape how they present themselves. It is expected, then, that the criminally involved women of color with severe mental illnesses in this thesis were aware of how their identities differed from that of the White, male researcher with whom they were sharing their stories. Research examining race-of-interviewer effects suggests that social and political power imbalances between White interviewers and the People of Color they interview has an impact on the ways in which participants talk about race and social status, two important factors of intersectionality (Rhodes, 1994; Schaeffer, 1980).

Existent research on race-of-interviewer effect has been fairly inconclusive. Some researchers have found that it can cause participants to be more inhibited or insincere when talking about sensitive topics while others have suggested that their status as an outsider in cross-racial interviews made participants feel more comfortable in discussing sensitive information (Rhodes, 1994; Websdale, 1998). In the context of research on the effects of interviewer gender, which typically finds that women will be more forthcoming when being interviewed by other women, the interaction of race, gender, and class differences between participant and interviewer is so prominent that it can effectively eliminate benefits associated with the interviewer's gender or race alone (Websdale, 1998; Riessman, 1987). Research on the effect of social differences between 
interviewers and participants on the content of the interview is often examined in conjunction with research on social desirability and stereotype threat, as they are fundamentally linked to each other.

Stereotype threat and social desirability scholarship argues that marginalized individuals will attempt to present themselves in a way that separates them from negative stereotypes associated with their race, gender, mental health, class, or some combination of their stigmatized social locations. Many of the women in this thesis indicated that they had endured stigmatization based on their criminal justice involvement, mental illness, and other facets of their identities, so it would make sense for them to feel motivated to discuss these sensitive topics in a way that is meant to both placate the interviewer and protect themselves from feelings of judgement by distancing themselves from these parts of their identity in their narratives (Davis \& Silver, 2003).

There are infinite variations of social statuses and identities that are applied to individuals and these identities shape the ways in which they might respond to similarly or differently situated individuals in a research setting. Therefore, we cannot expect to formulate a perfect and standardized combination of interviewers and participants that would eradicate the impact of social differences or similarities on the content of the interviews. Instead, we must acknowledge the complex identities of each of these individuals and how they operate in relation to each other to shape narratives.

\section{Conclusion}

The women interviewed for this project were all assigned to a SMI probation caseload due to the recognition that their mental illness and criminalization interacted with each other in a complicated way that necessitated a unique approach to their treatment and punishment. This understanding of the relationship between crime and mental health is a tremendous step towards embracing an intersectional view that acknowledges the interacting effects of status and identity. 
However, it fails to acknowledge the other parts of these individuals' that are deeply consequential in their experiences in the criminal justice and mental health system.

While contemporary criminology has demonstrated meaningful efforts to address the growing number of women, poor people, people of color, individuals with mental illness, and other variant populations in the criminal justice system, it can never be a truly comprehensive account of this age of mass incarceration as long as we continue to view those most affected by it as twodimensional, mutually exclusive categories of people. This mindset negates the complicated relationship between power and subordination that is distributed unequally to individuals based upon their intersectional location in society through a variety of ways. These structural mechanisms of social control are commonly manifested through crime control policies that protect the authority of certain groups of people through the domination of others.

Those in the position of most power have toted tough on crime policies and declared war on the most vulnerable citizens for non-violent drug offenses with such ferocity that the United States now boasts one of the highest incarcerations rates per capita in the developed world (International Centre for Prison Studies, 2013). This statistic has been exacerbated by the breakdown of community services for underprivileged and stigmatized Americans, such as the criminalized women of color with mental illness in this sample, in conjunction with the heightened surveillance and punishment of those same individuals, which has generated considerable diversity amongst criminally involved populations. For this reason, it is imperative that criminologists adopt a framework of intersectional criminology that is inclusive of identities and social positions as numerous and variable as the ones that are represented in our prisons, jails, and probation offices.

The criminally involved women of color with mental illnesses in this sample illuminated a myriad of ways in which their multiply stigmatized statuses interacted and culminated in 
disparately higher rates of medicalization, incarceration, substance abuse issues, and uniquely situated their life experiences in a way that exacerbated these issues. Given the rising numbers of women of color with mental illness in the criminal justice system, it would be remiss to continue treating all female offenders, all offenders with mental illness, or all minority offenders as mutually exclusive populations. Instead, criminological research should be fundamentally rooted in the contemplation of the role of intersectionality in any and all questions about crime if we hope to ever truly understand the unique lived experiences of the individuals we examine. 


\section{REFERENCES}

Abe-Kim, J., Takeuchi, D., Hong, S., Zane, N., Sue, S., Spencer, M.,...Alegría, M. (2007). Use of mental health-related services among immigrant and US-born Asian Americans:

Results from the National Latino and Asian American Study. American Journal of Public Health, 97(1), 91-98.

Abney, V. \& Priest, R. (1995). African Americans and sexual child abuse. In L. Fontes (Ed.), Sexual abuse in nine Northern American cultures: Treatment and prevention (pp. 11-30). Thousand Oaks, CA: Sage.

Abramsky, S. \& Fellner, J. (2003). Ill-equipped: U.S. Prisons and offenders with mental illness. New York: Human Rights Watch.

Adam, H. (1914). Women and Crime. London: Werner Lourie.

Alcoff, L. (1988). Cultural feminism vs. post-structuralism: The identity crisis in feminist theory. Signs, 13, 405-436.

Alegria, M., Canino, G., Rios, R., Vera, M., Calderon, J., Rusch, D. (2002). Inequalities in use of specialty mental health services among Latinos, African Americans, and non-Latino whites. Psychiatric Services, 53, 1547-1555.

Alegria, M., Mulvaney-Day, N., Woo, M., Torres, M., Gao, S., \& Oddo, V. (2007a). Correlates of past-year mental health service use among Latinos: Results from the National Latino and Asian American Study. American Journal of Public Health, 97, 76-83.

Alegria, M., Mulvaney-Day, N., Torres, M., Polo, A., Cao, Z., \& Canino, G. (2007b). Prevalence of psychiatric disorders across Latino subgroups in the United States. American Journal of Public Health, 97, 68-75. 
Alexander, M. (2010). The new Jim Crow: Mass incarceration in the age of colorblindness. New York: New Press.

Alvarez, A. \& Bachman, R. (1996). American Indians and sentencing disparities: An Arizona test. Journal of Criminal Justice, (24)6, 549-561.

Alvidrez, J. (1999). Ethnic variations in mental health attitudes and service use among lowincome African American, Latina, and European American young women. Community Mental Health Journal, 35(6), 515-530.

American Civil Liberties Union. (2005). "Caught in the Net: The Impact of Drug Policies on Women and Families." http://www.aclu.org.

Anderson, M. (1996). Forward. In E. Chow, D. Wilkinson, \& M. Baca Zinn (Eds.), Race, class, and gender: Common bonds, different voices (pp. ix-xii). Thousand Oaks, CA: Sage.

Anderson, M. \& Collins, P. (2004). Race, class, and gender. (5 $5^{\text {th }}$ ed.). Belmont, CA: Wadsworth. Arnold, R. (1990). Processes of victimization and criminalization of Black women. Social Justice, 17(3(41)), 153-166.

Auerhahn, K. \& Leonard, E. (2000). Docile bodies? Chemical restraints and the female inmate. The Journal of Criminal Law and Criminology, 90(2).

Ayman, R \& Korabik, K. (2010). "Leadership: Why gender and culture matter.” American Psychologist, 62(9), 949-79.

Baca Zinn, M. \& Thornton Dill, B. (1996). Theorizing difference from multiracial feminism. Feminist Studies, 22, 321-331. 
Baca Zinn, M. \& Wells, B. (1999). Diversity within Latino families: New lessons for family social science. In D. Demo, K. Allen, \& M. Fine (Eds.), The handbook of family diversity (pp. 252-273). Oxford University Press.

Baca Zinn, M., Hondagneu-Sotelo, P., \& Messner, M. (2005). Gender through the prism of difference. ( $3^{\text {rd }}$ ed.). New York, NY: Oxford University Press.

Barak, G. (1998). Integrating criminologies. Boston: Allyn \& Bacon.

Barak, G. (2003). Violence and nonviolence: Pathways to understanding. Thousand Oaks, CA: Sage.

Barak, G., Leighton, P., \& Cotton, A. (2015). Class, race, gender, and crime: the social realities of justice in America (4 ${ }^{\text {th }}$ ed.). Lanham: Rowman \& Littlefield.

Baskin, D., Sommers, I., Tessler, R., \& Steadman, H. (1989). Role incongruence and gender variation in the prison mental health services. Journal of Health and Social Behavior, 30, $305-314$

Beals, J., Novins, D., Whitesell, N., Spice, P., Mitchell, C., \& Manson, S. (2005). Prevalence of mental disorders and utilization of mental health services in two American Indian reservation populations: Mental health disparities in a national context. American Journal of Psychiatry, 162(9), 1723-1732.

Beck, A. (2005). Prisoners in 2004 (Report number 210677). Washington, D.C.: Bureau of Justice Statistics, U.S. Department of Justice.

Belknap, J. (2000) The Invisible Woman: Gender, Crime, and Justice. Australia ; Belmont, CA: Wadsworth. 
Bermúdez, J., Stinson, M., Zak-Hunter, L., \& Abrams, B. (2011). Mejor sola que mal acompañada: Strengths and challenges of Mexican-origin mothers parenting alone. Journal of Divorce \& Remarriage, 52, 622-641.

Bernard, A. (2013). The intersectional alternative: Explaining female criminality. Feminist Criminology, 8(1), 3-19.

Berrington, E. \& Honkatukia, P. (2002). “An evil monster and a poor thing: Female violence in the media." Journal of Scandinavian Studies in Criminology and Crime Prevention, 3(1), $50-72$.

Binswanger, I., Stern, M., Devo, R., Heagerty, P., Cheadle, A., Elmore, J., \& Knepsell, T. (2007). Release from prison: A high risk of death among former inmates. New England Journal of Medicine, 356(2), 157-65.

Black, D. \& Mileski, M. (1973). The social organization of law. New York: Seminar Form.

Blanco, C., Patel, S., Liu, L., Jiang, H., Lewis-Fernandez, R., Schmidt, A. (2007). National trends in ethnic disparities in mental health care. Medical Care, 45, 1012-1019.

Bloom, B., Owen, B., \& Covington, S. (2003) Gender-responsive strategies: Research, practice, and guiding principles for women offenders. Washington, D.C.: National Institute of Corrections.

Bloom, B., Owen, B., \& Covington, S. (2004). Women offenders and the gendered effects of public policy. Review of Policy Research, 21(1), 31-48.

Blum, R., Harmon, B., Harris, L., Bergeison, L., \& Resnick, M. (1992). American Indian-Alaska Native youth health. Journal of the American Medical Association, 267(12), 1637-1644.

Boeije, H. (2002). A purposeful approach to the constant comparative method in the analysis of qualitative interviews. Quality \& Quantity, 36, 391-409. 
Bohn, D. (2003). Lifetime physical and sexual abuse, substance abuse, depression, and suicide attempts among Native American women. Issues in Mental Health Nursing, 24(3), 333352.

Bolen, R. (1998). Predicting risk to be sexually abused: A comparison of logistic regression to event history analysis. Child Maltreatment, 3(2), 157-170.

Boritch, H. \& Hagan, J. (1990). A century of crime in Toronto: Gender, class, and patterns of social control, 1859 to 1955 . Criminology, 28(4), 567-599.

Brantley, M., Footer, K., Lim, S., Kerrigan, D., Sherman, S. (2017). Experiences of structural vulnerability among exotic dancers in Baltimore, Maryland: Co-occurring social and economic antecedents of HIV/STI risk. International Journal of Drug Policy, 50, 74-81.

Brave Heart, M. (1995). The return to the sacred path: Healing from unresolved grief among the Lakota and Dakota. Ph.D. dissertation, Smith College.

Brave Heart, M. \& DeBruyn, L. (1996). So she may walk in the balance: Integrating the impact of historical trauma in the treatment of Native American women. In J. Adleman. \& G. Enguidanos (Eds.), Racism in the lives of women: Testimony, theory, and guides to antiracist practice (pp. 171-205). New York: Hayworth Press.

Brennan, P. (2006). Sentencing female misdemeanants: An examination of the direct and indirect effects of race/ethnicity. Justice Quarterly, 23(1), 60-95.

Brewer, R. \& Heitzeg, N. (2008). The racialization of crime and punishment: Criminal justice, color-blind racism, and the political economy of the prison industrial complex. American Behavioral Scientist, 51(5), 625-644. 
Bridges, G. \& Beretta, G. (1994). Gender, race, and social control; Toward an understanding of sex disparities in imprisonment. In G. Bridges \& M. Myers (Eds.), Inequality, crime, and social control (pp. 158-175). Boulder, CO: Westview Press.

Bridges, G. \& Steen, S. (1998). Racial disparities in official assessments of juvenile offenders: Attributional stereotypes as mediating mechanisms. American Sociological Review, $63(4), 554$.

Britton, D. (2004). Feminism in criminology: Engendering the outlaw. In P. Schram, \& B. Koons-Witt, B. (Eds.), Gendered (in)justice: Theory and practice in feminist criminology (pp. 49-67). Long Grove, IL: Waveland Press.

Brown, B. (1986). Women and crime: The dark figures of criminology. Economy and Society, $15(3), 355-402$.

Burgess-Proctor, A. (2006). Intersections of race, class, gender, and crime: Future directions for feminist criminology. Feminist Criminology, 1(1), 27-47.

Bush-Baskette, S. (1998). “The War on Drugs as a War against Black Women,” in S. Miller (Ed.), Crime control and women: Feminist implications of criminal justice policy (113129). New York: Sage Publications.

Butler, A. (1997). Gendered justice in the American west: Women prisoners in men's penitentiaries. Urbana: University of Illinois Press.

Canaan, A. (2015). Brownness. In C. Moraga, \& G. Anzaldúa (Eds.), This bridge called my back: Writings by radical women of color (pp. 232-237). New York: SUNY Press.

Cantón-Cortés, D. \& Cantón, J. (2010). Coping with child sexual abuse among college students and post-traumatic stress disorder: The role of continuity of abuse and relationship with the perpetrator. Child Abuse \& Neglect, 34, 496-506. 
Carlen, P. (2002). Women and punishment: The struggle for justice. Willan.

Carpenter, M. (1864). Our Convicts, vol. I and II. London: Longman, Green, Longman, Roberts, and Green.

Carson, E. (2018). Prisoners in 2016. Retrieved from:

http://www.bjs.gov/index.cfm?ty=pbdetail\&iid $=6187$

Castro, D. (1998). 'Hot blood and easy virtue': Mass media and the making of racist Latino/a stereotypes. In C. Mann \& M. Zatz (Eds.), Images of color, images of crime (pp. 134144). Los Angeles: Roxbury.

Chang, S. \& Kleiner, B. (2003). Common racial stereotypes. Equal Opportunities International, $22(3), 1-9$.

Charmaz, K. (2008). Constructionism and the grounded theory model. Handbook of Constructionist Research, 1, 397-412.

Chesney-Lind, M. (1996). Sentencing women to prison: Equality without justice. In M. Schwartz \& D. Milovanovic (Eds.), Race, gender, and class in criminology: The intersections. (pp. 127-150). New York: Garland.

Chesney-Lind, M. (2006). Patriarchy, crime, and justice: Feminist criminology in the era of backlash. Feminist Criminology 1(1):6-26.

Chigwada-Bailey, R. (2008). Black women's experiences of criminal justice. Waterside Press.

Cicourel, A. (1968). The social organization of juvenile justice. New York: John Wiley.

Clement, S., Schauman, O., Graham, T., Maggioni, F., Evans-Lacko, S., Bezborodovs, N., ...Thornicroft. (2015). What is the impact of mental health-related stigma on helpseeking? A systematic review of quantitative and qualitative studies. Psychological Medicine, 45, 11-27. 
Conaghan, J. (2008). Intersectionality and the feminist project in law. In E. Grabham, D. Cooper, J. Kirshnadas, \& D. Herman (Eds.), Intersectionality and beyond: Law, power, and the politics of location (pp. 37-64). New York: Routledge.

Cooper, A. (1990 [1834]). A voice from the south. New York: Oxford University Press.

Corbin, J. \& Morse, J. (2003) Interactive interview: Issues of reciprocity and risks when dealing with sensitive topic. Qualitative Inquiry. 9(3), 335-354.

Corrigan, P. (2004). How stigma interferes with mental health care. American Psychologist, $59(7), 614-625$.

Crenshaw, K. (1989). Demarginalizing the intersection of race and sex: A Black feminist critique of antidiscrimination doctrine, feminist theory, and antiracial politics. University of Chicago Legal Forum, 1989(1).

Crenshaw, K. (1991). Mapping the margins: Intersectionality, identity politics, and violence against women of color. Stanford Law Review, 43, 1241-1299.

Crenshaw, K. (2012). From private violence to mass incarceration: Thinking intersectionally about women, race, and social control. UCLA Law Review, 59, 1418-1472.

Creswell, J. (2016). 30 essential skills for the qualitative researcher. Sage Publications.

Daly, K. (1992). Women's pathways to felony court: Feminist theories of lawbreaking and problems of representation. Southern California Review of Law \& Women's Studies, 2, 11.

Daly, K. (1993). Class-race-gender: Sloganeering in search of meaning. Social Justice, 20, 5671. 
Daly, K. \& Stephens, D. (1995). The “dark figure” of criminology: Towards a Black and multiethnic feminist agenda for theory and research. In N. Hahn \& F. Heidensohn (Eds.), International feminist perspectives in criminology: Engendering a discipline (pp.189215). Philadelphia: Open University Press.

Danner, M. (1999). Gender inequality and criminalization: A social feminist perspective on the legal social control of women. In M. Schwartz \& D. Milovanovic (Eds.), Race, gender, and class in criminology: The intersections (p. 29-48), New York: Garland Pub.

Datchi, C. \& Ancis, J. (2017). Gender, psychology, and justice: the mental health of women and girls in the legal system. New York: New York University Press.

Davis, A. (2003). Are prisons obsolete? New York: Seven Stories Press

Davis, D. \& Silver, B. (2003). Stereotype threat and race of interviewer effects in a survey on political knowledge. American Journal of Political Science, 47(1), 33-45.

Davis, K. (2008). Intersectionality as buzzword: A sociology of science perspective on what makes a feminist theory successful. Feminist Theory, 9(1), 67-85.

De'Andrea, M. (1994). The concerns of Native American youth. Journal of Multicultural Counseling and Development, 22, 173-181.

Díaz-Cotto, J. (2006). Chicana lives and criminal justice: Voices from el barrio. University of Texas Press.

Dickerson, F., Sommerville, J., Origoni, A., Ringel, N., \& Parente, F. (2002). Experiences of stigma among outpatients with schizophrenia. Schizophrenia Bulletin, 28(1), 143-155.

Ditton, P. (1999). Mental health and treatment of inmates and probationers. Washington, D.C.: U.S. Department of Justice, Office of Justice Programs, Bureau of Justice Statistics. 
Dohrenwend, B. \& Dohrenwend, B. (1969). Social status of psychological disorder. New York: Wiley.

Dohrenwend, B. \& Dohrenwend, B. (1974). Stressful life events; Their nature and effects. New York: Wiley.

Draine, J., Salzer, M., Culhane, D., \& Hadley, T. (2002). Role of social disadvantage in crime, joblessness, and homelessness among persons with serious mental illness. Psychiatric Services, 53(5), 565-573.

Drug Policy Alliance. (2016). Fact Sheet: Women, Prison, and the Drug War. Retrieved from: https://www.drugpolicy.org/sites/default/files/DPA_Fact\%20Sheet_Women\%20Prison\% 20and\%20Drug\%20War\%20\%28Feb.\%202016\%29.pdf

Duran, B., Sanders, M., Skipper, B., Waitzkin, H., Malcoe, L., Paine, S., \& Yager, J. (2004). Prevalence and correlates of mental disorder among Native American women in primary care. American Journal of Public Health, 94(1), 71-77.

Durham, M. (1989). The impact of deinstitutionalization on the current treatment of the mentally ill. International Journal of Law and Psychiatry, 12, 117-131.

Eack, S., Bahorik, A., Newhill, C., Neighbors, H., \& Davis, L. (2012). Interviewer-perceived honesty as a mediator of racial disparities in the diagnosis of schizophrenia. Psychiatric Services, 63, 875-880.

Eagle Russett, C. (1989). Sexual Science: The Victorian Construction of Motherhood. Cambridge, MA: Harvard University Press.

Entmacher, J., Robbins, K., Vogtman, J., \& Morrison, A. (2014). "Insecure and Unequal: Poverty and Income among Women and Families, 2000-2003.” Retrieved from: http://nwlc.org. 
Evans-Campbell, T., Lindorst, T., Huang, B., Walters, K. (2006). Interpersonal violence in the lives of urban American Indian and Alaska Native women: Implications for health, mental health, and help-seeking. American Journal of Public Health, 96(8), 1416-1422.

Farley, M., Lynne, J., \& Cotton, A. (2005). Prostitution in Vancouver: Violence and the colonization of First Nations women. Transcult Psychiatry, 42, 242-271.

Feeley, M. \& Little, D. (1991). The vanishing female: The decline of women in the criminal process, 1687-1912. Law \& Society Review, 25, 719-757.

Flute, J., Grobsmith, E., \& Revenaugh, M. (1985). A generation at risk. American Indian youth in the Great Plains: A report from 15 reservations. New York: Association on American Indian Affairs.

Frerichs, R., Aneshensel, C., \& Clark, V. (1981). Prevalence of depression in Los Angeles County. American Journal of Epidemiology, 112, 691-699.

Gamble, S. (1999). The Routledge critical dictionary of feminism and postfeminism. New York: Routledge.

Garb, H. (1997). Racial bias, social class bias, and gender bias in clinical judgement. Clinical Psychology: Science and Practice, 4, 99-120.

Gándara, P. (2015). Fulfilling America's future: Latinas in the U.S., 2015. Washington, D.C.: The White House Initiative on Educational Excellence for Hispanics.

Gentry, C. E., \& Sjoberg, L. (2015). Beyond mothers, monsters, whores: thinking about women's violence in global politics. London: Zed Books.

Glaser, B. \& Strauss, A. (1967). Grounded theory: The discovery of grounded theory. Sociology: The Journal of the British Sociological Association, 12, 27-49. 
Glick, P. \& Fiske, S. (1996). The Ambivalent Sexism Inventory: Differentiating hostile and benevolent sexism. Journal of Personality and Social Psychology, 70, 491-512.

Glick, R. \& Neto, V. (1977). National study of women's correctional programs. Washington, D.C.: USGPO.

Glick, R. \& Neto, V. (1982). “National Study of Women’s Correctional programs.” In B. Price \& N. Sokoloff (Eds.), The criminal justice system and women (pp. 141-154). New York: Clark and Boardman.

Goodkind, S. (2005). Gender-specific services in the juvenile justice system: A critical examination. Affilia, 20, 52-70.

Gordon-Bradshaw, R. (1987). Asocial essay on special issues facing poor women of color. Women and Health, 12, 243-259.

Gosden, R. (2001). Punishing the patient: How psychiatrists misunderstand and mistreat schizophrenia. Australia: Melbourne Scribe Publications.

Green, P. (1996). Drug couriers: A new perspective. London: Quartet Books.

Grobsmith, E. (1989). The relationship between substance abuse and crime among Native American inmates in the Nebraska Department of Corrections. Human Organization, 48, 285-298.

Haft, M. (1976). Hustling for rights. Massachusetts: Lexington.

Hamby, S. \& Skupien, M. (1998). Domestic violence on the San Carlos Apache reservation: Rates, associated psychological symptoms, and current beliefs. IHS Primary Care Providers, 23, 103-106.

Harris, A. (1990). Race and essentialism in feminist legal theory. Stanford Law Review, 42, 1118. 
Harrison-Ross, P. \& Lawrence, J. (2009). Women in jail: Mental health care needs and service deficiencies. In R. Gido \& L. Dalley (Eds.), Women's mental health issues across the criminal justice system (pp. 117-128). Upper Saddle River, NJ: Pearson Prentice Hall.

Haverkamp, B. (1993). Confirmatory bias in hypothesis testing for client-identified and counselor self-generated hypotheses. Journal of Counseling Psychology, 40, 303-315.

Heindesohn, F. (1985). Women and crime. Basingstoke: Macmillan.

Hernandez-Truyol, B. (1998). Lad olvidadas - Gendered in justice/gendered injustice: Latinas, Fronteras, and the law. Gender, Race, \& Justice, 1, 353-404.

Hill Collins, P. (1990). Black feminist thought: Knowledge, consciousness, and the politics of the women's movement. Boston, MA: Unwin Hymen.

hooks, b. (1984). Feminist theory from margin to centre. Boston: South End Press.

Horwitz, A. (2002). The social control of mental illness. Clinton Corners, NY: Percheron Press.

Howe, A. (1990). Sweet dreams: Deinstitutionalizing young women. In R. Graycar (Ed.), Dissenting opinions: Feminist explorations in law and society. Sydney, Australia: Allen and Unwin.

Humphreys, M., Johnstone, E., MacMillan, J., \& Taylor, P. (1992). Dangerous behavior preceding first admissions for schizophrenia. The British Journal of Psychiatry, 161(4), 501-505.

Hurtado, A. (1989). Relating to privilege: Seduction and rejection in the subordination of White women and women of color. Signs: Journal of Women in Culture and Society, 14, 833855.

Indian Health Service. (1995) National Plan for Native American Health Services, Amended. Rockville, MD: U.S. Department of Health and Human Services. 
Indian Health Service (1999). Trends in Indian health 1998-1999. Washington, D.C.:

Department of Health and Human Services, Indian Health Service, Office of Public Health.

Indian Health Service. (2001). Trends in Indian health 1998-1999. Retrieved from: http://www.ihs.gov/PublicInfo/Publications/trends98.asp

International Centre for Prison Studies. (2013). World Prison Brief. Retrieved from: http://www.prisonstudies.org/world-prison-brief [January 2014].

James, D. \& Glaze, L. (2006). Mental health problems of prison and jail inmates. (NCJ 213600). Washington, D.C.: Bureau of Justice Statistics.

Jiwani, Y. (2006). Discourses of denial: Mediations of race, gender, and violence. Vancouver: University of British Columbia Press.

Johnson, J. \& Cameron, M. (2001). Barriers to providing effective mental health services to American Indians. Mental Health Services Research, 3(4), 215-223.

Johnson, R. \& Turner, L. (2003). Data collection strategies in mixed methods research. In
A. Tashakkori \& C. Teddlie (Eds.), Handbook of mixed methods in social and behavioral research (pp. 279-319). Thousand Oaks, CA: Sage.

Jordan, B., Schlenger, W., Fairbank, J., \& Caddell, J. (1996). Prevalence of psychiatric disorders among incarcerated women: II. Convicted felons entering prison. Archives of General Psychiatry, 53(6), 513-519.

Kaeble, D. (2018). Probation and Parole in the United States, 2016. Retrieved from: http://www.bjs.gov/index.cfm?ty=pbdetail\&iid $=6188$

Keefe, S. (1981). Folk medicine among urban Mexican Americans: Cultural persistence, change, and displacement. Hispanic Journal of Behavioral Sciences, 3, 41-58. 
Kerrison, M. (2015). White claims to illness and the race-based medicalization of addiction for drug-involved former prisoners. Harvard Journal on Racial \& Ethnic Justice, 31, $105-$ 128.

Kessler, R. (1979). Stress, social status, and psychological distress. Journal of Health and Social Behavior, 20, 259-272.

Kessler, R., Berglund, P., Demler, O. Jun, R., Koretz, D., Merikangas, K.,...Wang, P. (2003). The epidemiology of major depressive disorder: Results from the National Comorbidity Survey Replication (NCS-R). Jama, 289(23), 3095-3105.

Kessler, R., McGonagle, K., Zhao, S., Nelson, C., Hughes, M., Eshleman, S.,...Kendler, K. (1994). Lifetime and 12-month prevalence of DSM-III-R psychiatric disorders in the United States: Results from the National Comorbidity Survey. Archives of General Psychiatry, 51, 8-19.

Kopasci, R. \& Faulkner, A. (1988). The powers that might be: The unity of white and black feminists. Affilia: Journal of Women and Social Work, 3, 33-50.

Kruttschnitt, C., \& Savolainen, J. (2009). Ages of chivalry, places of paternalism: Gender and criminal sentencing in Finland. European Journal of Criminology, 6(3), 225-247.

Kutchins, H. \& Kirk, S. (1997). Making us crazy. DSM: The psychiatric bible and the creation of mental disorders. New York: The Free Press.

LaFromboise, T., Berman, J., \& Sohi, B. (1994). American Indian women. In L. Comas-Diaz \& B. Greene (Eds.) women of color: Integrative ethnic and elder identities in psychotherapy (pp. 30-71). New York: Guilford Press. 
Lamb, H., Weinberger, L., \& Gross, B. (1999). Community treatment of severely mentally ill offenders under the jurisdiction of the criminal justice system: A review. Psychiatric Services, 50(7), 907-913.

Leaf, P., Bruce, M., Tischler, G., \& Holzer, C. (1987). The relationship between demographic factors and attitudes towards mental health services. Journal of Community Psychology, $15,275-284$.

Legal Momentum: The Women's Legal Defense and Education Fund. (2010). “Ensuring the Economic and Personal Security of Women and Girls," Retrieved from: http://www.legalmomentum.org

Lemert, E. (1967). Human deviance, social problems, and social control. Eaglewood Cliffs, NJ: Prentice Hall.

Lewis, D. (1977). Black women offenders and criminal justice: Some theoretical considerations. In M. Warren (Ed.), Comparing Male and Female Offenders (pp. 89-105). Beverly Hills, CA: Sage.

Lewis, D. \& Bresler, L. (1981). Is there a way out? A community study of women in the San Francisco County Jail.

Lewis, G., Croft-Jeffreys, C., \& David, A. (1990). Are British psychiatrists racist? British Journal of Psychiatry, 157, 410-415.

Lilliot, E., Trott, E., Kellett, N., Green, A., \& Willging, C. (2017). Women, incarceration, and reentry: The revolving door of prisons. In C. Datchi \& J. Ancis (Eds.), Gender, psychology, and justice: The mental health of women and girls in the legal system (127150). New York: New York University Press. 
Lin Fu, K. (1987). Special health concerns of ethnic minority women. Public Health Reports, $102,12-14$.

Lish, M. (2016). People with mental illness in the criminal justice system: Answering a cry for help. Washington, D.C.: American Psychiatric Association Publishing.

Lombroso, C. \& Ferraro, W. (1895). The female offender. London: T. Fisher Unwin

Lord, E. (2002). Prison careers of mentally ill women. In H. Toch \& K. Adams (Eds.), Acting out: Maladaptive behavior in confinement (pp. 363-386). Washington, D.C.: American Psychological Association.

Lujan, C. (1995). Women warriors: American Indian women, crime, and alcohol. Women and Criminal Justice, 7, 9-33.

Lykke, N. (2010). Feminist studies: A guide to intersection theory, methodology, and writing. New York: Routledge.

Lynch, M. (1996). Class, race, gender, and criminology: Structured choices and the life course. In D. Milvanovic \& M. Schwartz, M. (Eds.), Race, gender, and class in criminology: The intersections (pp. 3-28). New York: Garland.

Maher, L. (1997). Sexed work: Gender, race, and resistance in a Brooklyn drug market. UK: Oxford University Press.

Maj, M. (2005). 'Psychiatric comorbidity': An artefact of current diagnostic systems. British Journal of Psychiatry, 186, 182-184.

Mann, C. (1984). Female crime and delinquency. Montgomery: University of Alabama Press.

MCAPD. (2013). FY2013 Annual Report. Retrieved from http://www.superiorcourt.maricopa.gov/adultprobation/docs/2013annualreport.pdf 
MCAPD. (2018). Criminal/Mental Health. Retrieved from http://superiorcourt.maricopa.gov/criminal/criminal-mental-health

Markham, D. (2003). Mental illness and domestic violence: Implications for family law litigation. Clearinghouse Review Journal of Poverty Law and Policy, 37(1-2), 3-35.

Martell, D., Rosener, R., \& Harmon, R. (1995). Base-rate estimates of criminal behavior by homeless mentally ill persons in New York City. Psychiatric Services, 46, 596-601.

Mauer, M. (2013). The Changing Racial Dynamics of Women's Incarceration. Retrieved from: http://www.sentencingproject.org

May, P. (1986). Alcohol drug misuse prevention programs for American Indians: Needs and opportunities. Journal of Studies on Alcohol, 47, 187-195.

May, P. (1987). Suicide and self-destruction among American Indian youths. American Indian and Alaska Native Mental Health Research, 1(1), 52-69.

McGrath, E., Keita, G., Strickland, B., Russo, N. (1990). Women and depression: Risk factors and treatment issues. Washington, D.C.: American Psychological Association.

McKenzie, K., Samele, C., Van Horn, E., Tattan, T., Van Os, J., \& Murray R. (2001). Comparison of the outcome and treatment of psychosis in people of Caribbean origin living in the UK and British whites. The British Journal of Psychiatry, 178, 160-165.

McMahon, J. \& Kahn, K. (2015). Benevolent racism? The impact of target race on ambivalent sexism. Group Processes \& Intergroup Relations, 1-15.

Mehrotra, G. (2010). Toward a continuum of intersectionality: Theorizing for feminist social work scholarship. Affilia: Journal of Women and Social Work, 25, 417-430. 
Minior, T., Galea, S., Stuber, J., Ahern, J., \& Ompad, D. (2003). Racial differences in discrimination experiences and responses among minority substance abusers. Ethnicity \& Disease, 13, 521-527.

Minton, T. \& Golinelli, D. (2014). Jail inmates at midyear 2013-Statistical tables. Bureau of Justice Statistics. Washington, DC: USGPO.

Miller, J. \& Glassner, B. (2011). Interviews and focus groups. Qualitative research.

Morash, M. (2010). Women on Probation and Parole: A Feminist Critique of Community Programs and Services. Boston: Northeastern University Press.

Moulds, E. (1980). Chivalry and paternalism: Disparities of treatment in the criminal justice system. In S. Datesman and F. Scarpitti (Eds.), Women crime and justice (pp. 277-299). New York: Oxford University Press.

Moynihan, D. (1993). Defining deviancy down. American Scholar, 62(1), 17-30.

Mukherjee, S., Shukla, S., Woodle, J., Rosen, A., \& Olarte, S. (1983). Misdiagnosis of schizophrenia in bipolar patients: A multiethnic comparison. American Journal of Psychiatry, 140, 1571-1574.

Mulvey, P. (2013). On the Brink: Experiences of Women with Mental Illness on Probation. (Doctoral dissertation). Arizona State University.

Muñoz, A. \& Martínez, M. (2001). Latinas and criminal sentencing: An exploratory analysis. Voces: A journal of Chicana/Latina studies, 3(1/2), 150-176.

Murphy, Y. (2009). Incorporating intersectionality in social work practice, research, policy, and education. Washington, D.C.: NASW Press, National Association of Social Workers. 
Nadeem, E., Lange, J., Edge, D., Fongwa, M., Belin, T., \& Miranda, J. (2007). Does stigma keep poor young immigrant and U.S.-born Black and Latina women from seeking mental health care? Psychiatric Services, 58(12).

Nagel, L. \& Hagan, J. (1983). “Gender and crime; Offense patterns and criminal court sanctions.” In N. Morris \& M. Tonry (Eds.), Crime and Justice, Volume IV (pp. 91-144). Chicago, IL: University of Chicago Press.

Napholz, L. (1995). Mental health and American Indian women's multiple roles. American Indian and Alaska Native Mental Health Research, 6(2), 57-75.

Narayan, U. (1997). Contesting cultures, "Westernization," respect for cultures, and third-world feminism. In L. Nicholson (Ed.), The second wave: A reader in feminist theory (pp. 396414). New York: Routledge.

National Alliance on Mental Illness. “African American Mental Health”. Retrieved from: https://www.nami.org/Find-Support/Diverse-Communities/African-Americans.

Nawka, A., Kalisova, L., Raboch, J., Giacco, D., Cihal, L., Onchev, G.,...Kallert, T. (2013). Gender differences in coerced patients with schizophrenia. BioMed Central Psychiatry, $13,257-267$.

Neighbors, H., Caldwell, C., Williams, D., Nesse, R., Taylor, R., Bullard, K.,...Jackson, J. (2007) Race, ethnicity, and the use of services for mental disorders: Results from the National Survey of American Live. Archives of General Psychiatry, 64(4), 485-494.

Neighbors, H., Jackson, J., Campbell, L., \& Williams, D. (1989). The influence of racial factors on psychiatric diagnosis: A review and suggestions for research. Community Mental Health Journal, 25, 301-311. 
Neville, H., Worthington, R., \& Spanierman, L. (2001). Understanding white privilege and color-blind racial attitudes. Handbook of Multicultural Counseling, 257-288.

Nunn, K. (2002). Race, crime, and the pool of surplus criminality: Or why the "War on Drugs" was a "War on Blacks". Gender, Race, and Justice, 6, 381-445.

Ocen, P. (2012). The newly racialized restrictive covenant: Race, welfare, and the policing of Black women in subsidized housing. UCLA Law Review, 59.

Ocen, P. (2013). Unshackling intersectionality. Du Bois Review: Social Science Research on Race, $10(2), 471-483$.

Offen, L. (1986). The female offender and psychiatric referral: The medicalization of female deviance? Medicine and Law, 5, 339-348.

Omi, M. \& Winant, H. (1994). Racial formation in the United States. $2^{\text {nd }}$ ed. New York: Routledge.

Oparah, J. (2005). Global lockdown: Race, gender, and the prison-industrial complex. New York: Routledge.

Oparah, J. (2012). Feminism and the (trans)gender entrapment of non-conforming prisoners. UCLA Law Review, 18(2), 239-272.

Padgett, D., Patrick, C., Burns, B., \& Schlesinger, H. (1994a). Ethnicity and the use of outpatient mental health services in a national insured population. American Journal of Public Health, 84, 222-226.

Padgett, D., Patrick, C., Burns, B., \& Schlesinger, H. (1994b). Women and outpatient mental health services: Use by Black, Hispanic, and White women in a national insured population. Journal of Mental Health Administration, 21, 347-360. 
Padilla, A. \& Salgado de Snyder, V. (1988). Psychology in pre-Columbian Mexico. Hispanic Journal of the Behavioral Sciences, 10, 55-66.

Pager, D. (2007). Marked: Race, crime, and finding work in an era of mass incarceration. Chicago: The University of Chicago Press.

Penn, D., Kommana, S., Mansfield, M., \& Link, B. (1999). Dispelling the stigma of schizophrenia: II. The impact of information on dangerousness. Schizophrenia Bulletin, $25(3), 437-446$.

Perry, B. (2006). Nobody trusts them! Under- and over-policing Native American communities. Critical Criminology, 14(4), 411-444.

Perry, B., Neltner, M., \& Allen, T. (2013). A paradox of bias: Racial differences in forensic psychiatric diagnoses and determinations of criminal responsibility. Race and Social Problems, 5, 239-248.

Peterson, R. \& Hagan, J. (1984). Changing conceptions of race: Towards an account of anomalous findings of sentencing research. American Sociological Review, 49, 56-70.

Pharris, M., Resnick, M., \& Blum, R. (1997). Protecting against hopelessness and suicidality in sexually abused American Indian adolescents. Journal of Adolescent Health, 21(6), 400406.

Portillos, E. (1998). Latinos, gangs, and drugs. In C. Mann \& M. Zatz (Eds.) Images of color, images of crime (pp. 156-165). Los Angeles: Roxbury.

Potter, H. (2013). Intersectional criminology: Interrogating identity and power in criminological research and theory. Critical Criminology, 21(3), 305-318.

Poupart, L. (2002). Crime and justice in American Indian communities. Social Justice, 29(8788), 144-159. 
Rafter, N. (1985). Partial justice: Women in state prisons, 1800-1935. Boston: Northeastern University Press.

Rennison, C. (2001). Violent victimization and race, 1993-1998. (NCJ No. 176354). Washington, D.C.: U.S. Department of Justice, Office of Justice Programs, National Institute of Justice.

Rhodes, P. (1994). Race-of-interviewer effects: A brief comment. Sociology, 28(2), 547-558. Rice, M. (2016). Challenging orthodoxies in feminist theory: A black feminist critique. In Walklate: Gender and Crime, Vol. I. (pp. 296-310). New York: Routledge.

Richie, B. (1996). Compelled to crime: The gender entrapment of Black battered women. New York: Routledge.

Riessman, C. (1987). When gender is not enough: Women interviewing women. Gender \& Society, 1(2), 172-207

Ritchie, A. (2017). Invisible no more: Police violence against black women and women of color. Boston: Beacon Press.

Robin, R., Chester, B., Rasmussen, K., Jaranson, J., \& Goldman, J. (1997). Prevalence and characteristics of trauma and posttraumatic stress disorder in a south-western American Indian community. American Journal of Psychiatry, 154(11), 1582-1588.

Rojas, E., Smith, L., \& Scott-McLaughlin II, R. (2017). Women, poverty, and the criminal justice system: Cyclical linkages. In C. Datchi \& J. Ancis (Eds.), Gender, psychology, and justice: the mental health of women and girls in the legal system. New York: New York University Press. 
Rowan-Szal, G., Joe, G., Simpson, D., Greener, J., \& Vance, J. (2009). During-treatment outcome among female methamphetamine-using offenders in prison-based treatments. Journal of Offender Rehabilitation 48(5), 388-401.

Ruiz, P. (2002). Commentary: Hispanic access to health/mental health services. Psychiatric Quarterly, 73, 85-92.

Russell, D. (1984). The prevalence and seriousness of incestuous abuse: Stepfathers vs. biological fathers. Child Abuse and Neglect: The International Journal, 8(1), 15-22

Russell, D. (1986). The secret trauma: Incest in the lives of girls and women. New York: Basic Books, Inc.

Sandberg, L. (2013). Backward, dumb, and violent hillbillies? Rural geographies and intersectional studies on intimate partner violence. Affilia: Journal of Women and Social Work, 28(4), 350-365.

Sanders, T. (2007). Becoming an ex-sex worker: Making transitions out of a deviant career. Feminist Criminology, 2(1), 74-95.

Sanguineti, V., Samuel, S., Schwartz, S., Robeson, M. (1996). Retrospective study of 2,200 involuntary psychiatric admissions and readmissions. American Journal of Psychiatry, 153, 392-396.

Schaeffer, N. (1980). Evaluating race-of-interviewer effects in a national survey. Sociological Methods and Research, 8(4), 400-419.

Scheffler, R. \& Miller, A. (1989). Demand analysis of mental health service use among ethnic subpopulations. Inquiry, 26, 202-215. 
Schultz, A., Williams, D., Israel, B., Becker, A., Parker, E., \& James, J. (2000). Unfair treatment, neighborhood effects, and mental health in the Detroit metropolitan area. Journal of Health and Social Behavior, 41, 314-332.

Schur, E. (1984). Labeling women deviant: Gender, stigma, and social control. New York: Random House.

Schwartz, R. \& Blankenship, D. (2014). Racial disparities in psychotic disorder diagnosis: A review of empirical literature. World Journal of Psychiatry, 4(4), 133-140.

Schwartz, R. \& Feisthamel, K. (2009). Disproportionate diagnosis of mental disorders among African American versus European American clients: Implications for counseling theory, research, and practice. Journal of Counseling and Development, 87, 295-301.

Settles, I. (2006). Use of an intersectional framework to understand Black women's racial and gender identities. Sex Roles, 54(9-10), 589-601.

Shadish, W., Lurigio, A., \& Lewis, D. (1989). After deinstitutionalization: The present and future of mental health long-term care policy. Journal of Social Issues, 45(3), 1-15.

Sharac, J., McCrone, P., Clement, S., \& Thornicroft, G. (2010). The economic impact of mental health stigma and discrimination: A systematic review. Epidemiologia e Psichiatria Sociale, 19(3), 223-232.

Sharpley, M., Hutchinson, G., Murray, R., \& McKenzie, K. (2001). Understanding the excess of psychosis among the African-Caribbean population in England: Review of current hypotheses. The British Journal of Psychiatry, 178(S40), 60-68. 
Shaw, N. (1982). Female patients and the medical profession in jails and prisons: A case of quintuple jeopardy. In N. Rafter \& E. Stanko (Eds.) Judge, lawyer, victim, thief: Women, gender roles, and criminal justice (pp. 261-265). Boston, MA: Northeastern University Press.

Siegal, R. (1997). Why equal protection no longer protects: The evolving forms of statusenforcing state action. Faculty Scholarship Series. Paper 1091.

Silva de Crane, R. \& Spielberger, C. (1981). Attitudes of Hispanic, Black, and Caucasian university students toward mental illness, Hispanic Journal of Behavioral Sciences, 3, 241-255.

Snipp, C. (1986). The changing political and economic status of the American Indians. American Journal of Economics and Sociology, 45, 145-158.

Snipp, C. (1992). Sociological perspectives on American Indians. Annual Review of Sociology, $18,351-371$.

Snow, L. (1983). Traditional health beliefs and practices among lower class Black Americans. Western Journal of Medicine, 139, 820-828.

Social Exclusion Unit [SEU]. (2002). Reducing re-offending by ex-prisoners. London: HMSO. Sokoloff, N. \& Dupont, I. (2005). Domestic violence at the intersections of race, class, and gender: Challenges and contributions to understanding violence against marginalized women in diverse communities. Violence Against Women, 11(1), 38-64.

Spieglman, R. (1977). Prison drugs, psychiatry, and the state. In D. Greenberg (Ed.) Corrections and punishment: 8 Sage criminal justice annuals (pp. 149-167). Beverly Hills, CA: Sage. Stannard, D. (1992). American Holocaust. New York: Oxford. 
Steffensmeier, D., Ulmer, J., \& Kramer, J. (1998). The interactions of race, gender, and age in criminal sentencing; The punishment cost of being young, Black, and male. Criminology, 36, 763-793.

Symington, A. (2004). Intersectionality: A tool for gender and economic justice. Women's Rights and Economic Change, 9.

Tausig, M., Michello, J., \& Subedi, S. (1999). A sociology of mental illness. Upper Saddle River, NJ: Prentice Hall.

Taylor, R. (1999). Diversity within African American Families. In D. Demo, K. Allen, \& M. Fine, (Eds.), The Handbook of Family Diversity (pp. 232-251). Oxford University Press.

Teplin, L., Abram, K. \& McClellan, G. (1996). Prevalence of psychiatric disorders among incarcerated women: I. Pretrial jail detainees. Archives of General Psychiatry, 53(6), 505512.

Thompson, G. (2013). African American women and the U.S. criminal justice system: A statistical survey, 1870-2009, The Journal of African American History, 98(2), 291-303.

Thompson, M. (2005). Race, gender, and mental illness in the criminal justice system. New York: LFB Scholarly Pub.

Thompson, M. (2010). Mad or bad? Race, class, gender, and mental illness in the criminal justice system.

Tjaden, P. \& Thoennes, N. (2000). Full report on the prevalence, incidence, and consequence of violence against women. Washington, D.C.: National Institute of Justice.

Tonry, M. (1994). Racial disproportions in US prisons. British Journal of Criminology, 34, 97.

Tonry, M. \& Farrington, D. (1995). Strategic approaches to crime prevention. Crime \& Justice, 19, 1-20. 
Torrey, E. (1997). Out of the shadows: Confronting America's mental illness crisis. New York: John Wiley \& Sons.

Trahan, A. (2011). Qualitative research and intersectionality. Critical Criminology, 19(1), 1-14.

Turanovic, J. \& Pratt, T. (2013). The consequences of maladaptive coping: Integrating general strain and self-control theories to specify a causal pathway between victimization and offending. Journal of Quantitative Criminology, 29, 321-345.

U.S. Census Bureau. (2002). US Summary: 2000. Retrieved from http://www.census.gov/prod/2002pubs/c2kprof00.pdf

U.S. Department of Health and Human Services. (2001). Mental health: Culture, race, and ethnicity: A supplement to mental health: A report of the surgeon general. Rockville, MD: U.S. Public Health Service.

U.S. Department of Justice, Bureau of Justice Statistics. (1998). Correctional populations in the United States, 1997. Washington, D.C.: USGPO.

U.S. Department of Justice. (1991). Drugs and Jail Inmates, 1989. Special Report NCJ-130836. Washington, D.C.: USGPO.

U.S. Department of Justice, Bureau of Justice Statistics. (2004). Sourcebook of criminal justice statistics. Washington, D.C.: USGPO.

U.S. Department of Justice, Bureau of Justice Statistics (2006a). Mental health problems of prison and jail inmates. Washington, D.C.: USGPO.

U.S. Department of Justice, Bureau of Justice Statistics. (2006b). Prison and jail inmates at midyear 2005. Washington, D.C.: USGPO.

Ulmer, J. \& Bradley, M. (2017). Punishment in Indian Country: Ironies of federal punishment of Native Americans. Justice Quarterly, 35(5), 751-781. 
Vespa, J. (2009). Gender ideology construction: A life course and intersectional approach. Gender \& Society, 23(3), 363-387.

Villarosa, L. (1994). Body and soul: The Black woman's guide to physical health and emotional well-being. New York: Harper Perennial.

Wang, P., Lane, M., Olfson, M., Pincus, H., Wells, K., \& Kessler, R. (2005). Twelve-month use of mental health services in the United States. Archives of General Psychiatry, 62, 629640.

Ward, E., Clark, L., \& Heidrich, S. (2009). African American women’s beliefs, coping behaviors, and barriers to seeking mental health services. Qualitative Health Research, 19(11), 1589-1601.

Warheit, G., Holzer, C., \& Avery, S. (1975). Race and mental illness: An epidemiologic update. Journal of Health and Social Behavior, 16, 243-256.

Warheit, G., Holzer, C., \& Schwab, J. (1973). An analysis of social class and racial differences in depressive symptomatology: A community study. Journal of Health and Social Behavior, 14, 291-299.

Warren, J., Hurt, S., Loper, A., Bale, R., Friend, R., \& Chauhan, P. (2002). Psychiatric symptoms, history of victimization, and violent behavior among incarcerated female felons: An American perspective. International Journal of Law and Psychiatry, 25, 129149.

Weber, L. (2010). Understanding race, class, gender, and sexuality: A conceptual framework. New York: Oxford University Press. 
Weber, L. \& Parra-Medina, D. (2003). Intersectionality and women's health: Charting a path to eliminating health disparities. In M. Segal, V. Demos, \& J. Kronenfeld (Eds.), Gender perspectives on health and medicine: Key themes (pp. 181-229). Oxford, UK: Elsevier.

Websdale, N. (1998). Rural women battering and the justice system: An ethnography. Sage.

Weinick, R., Zuvekas, S., \& Cohen, J. (2000). Racial and ethnic differences in access to and use of health care services, 1977 to 1996. Medical Care Research and Review, 57, 36-54.

Welch, D. (1987). American Indian women: Reaching beyond the myth. In C. Calloway (Ed.), New directions in American Indian history (pp. 31-48). Norman, OK: University of Oklahoma Press.

West, C. (1995). Mammy, Jezebel, and Sapphire: Historical images of black women and their implications for psychotherapy. Psychotherapy, 32, 458-466.

West, C. (2004). Mammy, Jezebel, and Sapphire: Developing an "oppositional gaze" toward the images of black women. In J. Chrisler, C. Golden, \& P. Rozee (Eds.) Lectures on the psychology of women ( $3^{\text {rd }}$ ed., pp. 237-252). Boston: McGraw-Hill.

Wilkenson, G. (1974). Colonialism through the media. The Indian Historian, 7, 29-32.

Willging, C., Malcoe, L., St. Cyr, S., Zywiak, W., \& Lapham, S. (2013). Behavioral health and social correlates of reincarceration among Hispanic, Native American, and White rural women. Psychiatric Services, 64(6), 590-593.

Wolff, N., Fabrikant, N., \& Belenko, S. (2011). Mental health courts and their selection processes: Modeling variation for consistency. Law and Human Behavior, 35(5), 402412.

Yates, A. (1987). Current status and future directions of research on the American Indian child. American Journal of Psychiatry, 144, 1135-1142. 
Young, V. (1986). “Gender Expectations and Their Impact on Black Female Offenders and Victims." Justice Quarterly, 3, 305-327.

Zaplin, R. (1999). Female offenders: Critical perspectives and effective interventions. Aspen: Aspen Pub.

Zatz, M., Lujan, C., \& Snyder-Joy, Z. (1991). American Indians and criminal justice: Some conceptual and methodological considerations. In M. Lynch \& E. Patterson (Eds.), Race and criminal justice (pp. 100-112). New York: Harrow and Heston.

Zedner, L. (1991). Women, crime, and custody in Victorian England. Oxford: Claredon Press. 
APPENDIX A: TABLES

\begin{tabular}{|c|c|c|c|}
\hline & $\begin{array}{c}\text { White } \\
\text { Women }\end{array}$ & $\begin{array}{l}\text { Women of } \\
\text { Color }\end{array}$ & Total \\
\hline Number of respondents & $\mathrm{n}=43$ & $\mathrm{n}=22$ & $\mathrm{n}=65$ \\
\hline \multicolumn{4}{|l|}{ Age (years) } \\
\hline Mean & 39.1 & 35.3 & 37.8 \\
\hline Median & 39 & 35 & 36 \\
\hline \multicolumn{4}{|l|}{ Race/Ethnicity } \\
\hline White & $43(100.0)$ & -- & $43(66.2)$ \\
\hline Black & -- & $12(54.5)$ & $12(18.5)$ \\
\hline Latina & -- & $5(22.7)$ & $5(7.7)$ \\
\hline Native American & -- & $3(13.6)$ & $3(4.6)$ \\
\hline Pacific Islander & -- & $2(9.1)$ & $2(3.1)$ \\
\hline \multicolumn{4}{|c|}{ Primary mental health diagnosis } \\
\hline Mood Type Disorder & $28(65.1)$ & $11(50.0)$ & $39(60.0)$ \\
\hline Psychotic Type Disorder & $10(23.3)$ & $10(45.4)$ & $20(30.8)$ \\
\hline Anxiety Type Disorder & $5(11.6)$ & $1(4.5)$ & $6(9.2)$ \\
\hline Psych medication & $40(93.0)$ & $21(95.5)$ & $61(93.8)$ \\
\hline Psych hospitalization & $33(76.7)$ & $16(72.7)$ & $49(75.4)$ \\
\hline \multicolumn{4}{|l|}{ Offense Type } \\
\hline Substance Related Offense & $15(34.9)$ & $7(31.8)$ & $22(33.8)$ \\
\hline Property Related Offense & $11(25.6)$ & $6(27.3)$ & $17(26.2)$ \\
\hline Violent Offense & $16(37.2)$ & $8(36.4)$ & $24(36.9)$ \\
\hline Other & $1(2.3)$ & $1(4.5)$ & $2(3.1)$ \\
\hline \multicolumn{4}{|l|}{ Previous incarceration } \\
\hline None & $3(7.0)$ & $2(9.1)$ & $5(7.7)$ \\
\hline Less than one year & $20(46.5)$ & $14(63.6)$ & $34(52.3)$ \\
\hline More than one year & $20(46.5)$ & $6(27.3)$ & $26(40.0)$ \\
\hline
\end{tabular}




\begin{tabular}{|lccc|}
\hline Table 2. Dual Diagnosis & & & \\
\hline & White Women & Women of Color & Total \\
\hline Number with 2+ diagnoses & $\mathrm{n}=25(58.1)$ & $\mathrm{n}=20(90.9)$ & $\mathrm{n}=45(69.2)$ \\
Mood/Psychotic Diagnoses & $4(16.0)$ & $11(45.0)$ & $15(33.3)$ \\
Mood-Psychotic & $2(8.0)$ & $4(20.0)$ & $6(13.3)$ \\
Psychotic-Mood & $2(8.0)$ & $7(35.0)$ & $9(20.0)$ \\
& & & \\
Mood/Anxiety Diagnoses & $6(24.0)$ & $4(20.0)$ & $10(22.2)$ \\
Mood-Anxiety & $5(20.0)$ & $3(15.0)$ & $8(17.8)$ \\
Anxiety-Mood & $1(4.0)$ & $1(5.0)$ & $2(4.0)$ \\
& & & \\
Other Diagnoses & $15(60.0)$ & $5(25.0)$ & $6(13.3)$ \\
Mood-Mood & $4(16.0)$ & $2(10.0)$ & $3(17.8)$ \\
Mood-Personality & $6(24.0)$ & $2(10.0)$ & $3(6.7)$ \\
Anxiety-Personality & $3(12.0)$ & -- & \\
Psychotic-Anxiety & $2(8.0)$ & $1(5.0)$ & \\
\hline
\end{tabular}




\begin{tabular}{|c|c|c|c|}
\hline & White Women & Women of Color & Total \\
\hline $\begin{array}{l}\text { Respondents with bipolar } \\
\text { disorder }\end{array}$ & $\mathrm{n}=28$ & $\mathrm{n}=11$ & $\mathrm{n}=39$ \\
\hline \multicolumn{4}{|l|}{ Type of crime } \\
\hline Drug & $9(32.1)$ & $2(18.2)$ & $11(28.2)$ \\
\hline Violent & $6(21.4)$ & $4(36.4)$ & $10(25.6)$ \\
\hline Property & $11(39.3)$ & $5(45.5)$ & $16(41.0)$ \\
\hline \multirow[t]{2}{*}{ Other } & $2(7.1)$ & -- & $2(5.0)$ \\
\hline & White Women & Women of Color & Total \\
\hline \multicolumn{3}{|l|}{$\begin{array}{l}\text { Respondents with psychotic disorder } \\
\mathrm{n}=10\end{array}$} & $\mathrm{n}=20$ \\
\hline \multicolumn{4}{|l|}{ Type of crime } \\
\hline Drug & $3(30.0)$ & $5(50.0)$ & $8(40.0)$ \\
\hline Violent & $6(60.0)$ & $4(40.0)$ & $10(50.0)$ \\
\hline Property & -- & $1(10.0)$ & $1(5.0)$ \\
\hline \multirow[t]{2}{*}{ Other } & $1(10.0)$ & -- & $1(5.0)$ \\
\hline & White Women & Women of Color & Total \\
\hline $\begin{array}{l}\text { Respondents with anxiety } \\
\text { disorder }\end{array}$ & $\mathrm{n}=5$ & $\mathrm{n}=1$ & $\mathrm{n}=6$ \\
\hline \multicolumn{4}{|l|}{ Type of crime } \\
\hline Drug & $3(60.0)$ & $1(100.0)$ & $4(66.6)$ \\
\hline Violent & $2(40.0)$ & -- & $2(33.3)$ \\
\hline Property & -- & -- & -- \\
\hline Other & -- & -- & -- \\
\hline
\end{tabular}

